Araştırma Makalesi - Research Article

\title{
Güvenlik Kültürü Bileşenlerinin Sağlıklı ve Güvenli İşyeri Oluşumuna Etkisi: Bir Büyükşehir Belediyesinde Ampirik Bir Uygulama
}

\section{The Effect of Safety Culture Dimensions on Healthy and Safe Workplace Environment: An Empirical Application in a Metropolitan Municipality}

\author{
Metin BAYRAM* \\ (iD) 0000-0002-9483-7850 \\ Bülent ARPAT** \\ (iD) 0000-0002-3512-9969 \\ ÖZ
}

İş kazası ve meslek hastalıkları ile mücadelenin temel gerekliliklerinden biri sağlıklı ve güvenli işyerinin oluşturulmasıdır. Sağlıklı ve güvenli işyeri oluşumu, sıklıkla güvenlik kültürü adı verilen çok boyutlu bir gizil değişken ile betimlenmektedir. Bu çalışmanın amacı, sağlıklı ve güvenli bir işyerinin oluşturulmasında güvenlik kültürü bileşenlerinin etkisini değerlendirmektedir. $\mathrm{Bu}$ amaçla 11 güvenlik kültürü bileşeni kullanılarak bir büyükșehir belediyesi örnekleminde uygulama yapılmıştır. Veri toplama için anket yönteminden faydalanılmıştır. Araştırma, nicel araştırma yönteminde ve betimsel tarama desenindedir. Araştırma analizlerinde Smart PLS yazılımı aracılığıyla doğrulayıcı faktör analizi ve yol analizi kullanılmıştır. Araştırma bulgularında güvenlik önceliği, yönetimin güvenlik bağlılığı, güvenlik eğitimi, güvenlik teşviki, güvenlik liderliği, güvenlik iletişimi, güvenlik farkındalığı, güvenli davranış, çalışan katılımı ve proses güvenliği bileşenlerinin sağlıklı ve güvenli işyeri oluşumuna olumlu katkı sağladığı kanıtlanmıştır. $\mathrm{Bu}$ bulguya göre işyerlerinde sağlıklı ve güvenli bir işyeri oluşturmak amacıyla anılan bileşenlerin ya da güvenlik kültürünün iyileştirilmesine dönük tüm eylemlerin, sağlıklı ve güvenli işyeri oluşumuna pozitif katkı sağlayacağ anlaşılmıştır.

Anahtar Sözcükler: Güvenlik kültürü, sağlıklı ve güvenli işyeri, iş sağlığı ve güvenliği

\begin{abstract}
One of the basic requirements of combating work accidents and occupational diseases is the creation of a healthy and safe workplace. Healthy and safe workplace formation is often described by a multidimensional latent variable called safety culture. The purpose of this study is to evaluate the effect of safety culture components on the creation of a healthy and safe workplace. For this purpose, an application was made in a sample of metropolitan municipality by using 11 safety culture components. Survey method was used for data collection. The research is in quantitative research method and descriptive survey design. Confirmatory factor analysis and path analysis via Smart PLS software were used in research analysis. In the findings of the research, it has been proven that safety priority, safety commitment of management, safety training, safety promotion, safety leadership, safety communication, safety awareness, safety behavior, employee participation and process safety components contribute positively to the formation of a healthy and safe workplace. According to this finding, it has been understood that the aforementioned components or all actions to improve the safety culture in order to create a healthy and safe workplace in workplaces will positively contribute to the formation of a healthy and safe workplace.
\end{abstract}

Keywords: Safety culture, healthy and safe workplace, occupational health and safety

Önerilen atıf şekli: Bayram, M. ve Arpat, B. (2021). Güvenlik Kültürü Bileşenlerinin Sağlıklı ve Güvenli İşyeri Oluşumuna Etkisi: Bir Büyükşehir Belediyesinde Ampirik Bir Uygulama. Sosyal Güvenlik Dergisi (Journal of Social Security). 11(1). 95-116

• Geliş Tarihi/Received: 16/02/2021 • Güncelleme Tarihi/Revised: 30/05/2021 • Kabul Tarihi/Accepted: 14/06/2021

\footnotetext{
* Dr. Öğr. Üyesi., Sakarya Üniversitesi, İşletme Fakültesi, İşletme Bölümü, metinbayram@sakarya.edu.tr

** Doç. Dr., Bandırma 17 Eylül Üniversitesi, Manyas Meslek Yüksek Okulu,

barpat@bandirma.edu.tr
} 


\section{GİRIŞ}

İş kazaları ve meslek hastalıkları tüm sektörler için tehlike arz eden, sosyal ve ekonomik bakımdan büyük kayıplara neden olan önemli bir tehdittir. Bu tehdit ile mücadelede "is sağllğı ve güvenliği (ISG)" biliminden faydalanılmaktadır. İSG önlemleri almak işverenin, önlemlere uymak ise çalşsanların sorumluluğundadır. Ancak salt bu nevi hukuki düzenlemeler ile sağlıklı ve güvenli işyerleri oluşturulamamaktadır. Çalışanların kas gücü ya da beyin gücü ile yürüttüğü çalışmalarda, ancak "gönül gücü” ile önlemlere riayet edilmesi halinde kayda değer bir İSG performansı elde edilebilmektedir. Gönül gücü ile kurallara uyum ise işyerinin, bireyin ve toplumun güvenliğe bakışı ile şekillenen pozitif bir güvenlik kültürünün kişisel bir tezahürüdür.

İş kazası ve meslek hastalıkları ile mücadelede "sağllklı ve güvenli işyerine" sıklıkla vurgu yapılmaktadır. Sağlıklı ve güvenli işyeri kavramı sadece teknik olarak ISG açısından yeterli işyeri ortamını değil aynı zamanda bireysel, örgütsel, yönetsel düzeyde yeterliliğe karşılık gelen komplike bir kavramdır. Bu çerçevede sağlıklı ve güvenli bir işyerinin özelliklerini, tipik olarak güvenlik kültürü ve bileşenleri ile betimlemek mümkündür. Arcury, Arnold, Mora, Sandberg, Daniel, Wiggins ve Quandt (2019: 1098), çocuk iş̧̧ilerin işyeri güvenliğine ilişkin görüşlerini belirlemeyi amaçladığı çalışmalarında, iş güvenliği kültüründen faydalanılması gerektiğini, güvenli bir işyeri algısına güvenlik kültürünün kavramsal bir çerçeve sağladığını belirtmektedir. Literatürde değişkenlik göstermekle birlikte genel kabul gören güvenlik kültürü bileşenlerini; güvenlik kuralları, güvenlik önceliği, yönetimin güvenlik bağlılı̆̆ı, güvenlik liderliği, güvenlik teşviki, güvenlik farkındalı̆̆ı, güvenli davranış, güvenlik katılımı, güvenlik eğitimi, güvenlik iletişimi ve proses güvenliği olarak sınıflamak mümkündür. Söz konusu bileşenlerin hiçbirini salt bireysel, örgütsel ya da yönetsel olarak kategorize etmek mümkün değildir. Zira bireyin tutum ve davranışlarını, içinde yaşadığı toplumun ve iş görme edimini yerine getirdiği işyerinin değerleri, normları, inançları ve sembolleri şekillendirmektedir. İşte bu nedenle anılan boyutlar (özellikler), gizil (örtük) olarak nitelenen güvenlik kültürü içeriğinde ele alınmaktadır.

Ulusal ekonomilerin gelişmişlik düzeyi, ülkenin sağlık ve güvenliğe ilişsin önemli göstergelerden biridir. Zira gelişmekte olan ve hızlı büyüyen ekonomilerin temel özelliklerinden biri, çalışanlarının sağlığı ve güvenliğinin korunmasında yaşanan zorluklardır. Hızlı büyüme etkinliğinin yetersiz teknoloji kullanımı, eski ekipman, düşük eğitim düzeyi ve kalıplaşmış (güvensiz davranış) alışkanlıklar ile birleşmesi durumunda daha çok sayıda tehditle, daha sık karşılaşııması olasıdır (Pınar, 2015: 1). Bu nedenle bu özelliklere sahip ekonomilerde kaza ve hastalıklardan korunmak için güvenlik kültürü tesisi ve uygulamaları daha elzemdir. Ancak hemen belirtelim ki, bu tip ekonomilerin düşük sermaye birikimi ve güvenlik konusundaki görece zayıf sosyo-kültürel yapıları, güvenlik kültürü oluşumunu genellikle zorlaştırıcı bir rol oynamaktadır. Bu nedenle, bu tip ekonomilerde sağlıklı ve güvenli işyerleri oluşturma ve güvenlik kültürünü iyileştirme üzerine yapılan araştırma ve uygulamaların, daha büyük katkılar sağlaması olasıdır.

$\mathrm{Bu}$ araştırma, (çeşitli boyutlarla açıklanan bir örtük değişken olan) güvenlik kültürünün, sağlıklı ve güvenli bir işyeri ortamı oluşturmada etkili bir unsur olduğunu kanıtlama gayretindedir. Araştırmanın ilk bölümü literatüre ve buna dayanarak hipotezlerin geliştirilmesine ayrılmıştır. İkinci bölümde yönteme, üçüncü bölümde bulgulara ve son bölümde ise tartışma ve sonuca yer verilmiş̧ir. 


\section{I- LITERATÜR VE HİPOTEZ GELISTTIRME}

\section{A- Güvenlik Kültürü Bileșenleri}

Güvenlik kültürüne ilişkin literatürde pek çok tanım yer almaktadır. Özkan ve Lajunen (2003: 3), çalışmasında güvenlik kültürünü "kurumun sağllk ve güvenlik programlarının yeterliliğine, tarzına ve uygulamadaki israrına karar veren birey ve grupların değer, tutum, yetkinlik ve davranış görüntülerinin bir ürünü”; Uttal (1983) “davranışsal normları ortaya koyan kontrol sistemleri ve örgütün yapısı ile etkileşime giren paylaşılan değer ve inançlar" ve Vredenburgh (2002: 260), “organizasyonda çalışanların maruz kaldı̆̆ tehlikelerin azaltılmasıyla ilgili tecrübeler, normlar, inançlar, roller ve tutumlar” olarak tanımlanmaktadır.

Güvenlik kültürü sadece işletme kültüründen etkilenmez, bununla birlikte işletmenin içinde bulunduğu toplumun kültüründen de etkilenmektedir. İşyerlerinde sağlıklı ve güvenli bir çalışma kültürü sağlamada temel amaç, çalışanların işyerindeki tehlike ve risklere karşı farkındalıklarını sağlamak ve güvenlik performansında sürekli iyileşmeyi sağlayacak tedbir ve kuralları geliştirmektir (Atan, Cam, Çelik, Arslan ve Eravcı, 2017: 112-113).

$\mathrm{Bu}$ çalışma için yapılan literatür taramasında, değişik yazarlar tarafindan farklı sektörler üzerinde yapılan güvenlik kültürü çalışmalarında, değişik sayı ve isimde boyutlar üzerinde çalışıldığı görülmektedir. Tekstil, metal, kimya ve gıda sektörleri üzerindeki Zohar (1980)'ın araştırmasında, güvenlik kültürünün sekiz boyutu tanıtılmaktadır. İnşaat sektörü üzerine yaptıkları çalışmalarında Dedobbleer ve Beland (1991) sadece iki güvenlik kültürü boyutundan bahsetmekte iken, Cox ve Cox (1991) beş boyut, Lee (1996) yirmi dört boyut ve Williamson vd. (1997) beş boyut üzerinde çalışmışlardır (Aktaran Demirbilek, 2005: 94). Türkiye'de ise otomotiv sektörü üzerinde yaptığ1 araştırmada Dursun (2012: 114) ve tekstil sektörü üzerindeki araştırmasında Demirbilek (2005: 160) sekiz boyut ile güvenlik kültürünü temsil etmişlerdir. Güvenlik kültürü çalışmalarında araştırmacıların kendi boyutlarını belirleme konusunda özgür olduğu ve önceki araştırmalara bağlı kalma zorunluluğu bulunmadığı iddia edilmektedir (Guldenmund, 2010: 35).

$\mathrm{Bu}$ araştırmanın yazarları tarafından da yukarıdaki araştırmalarda bulunan benzer veya aynı boyutları içeren 11 boyut tespit edilmiştir; güvenlik kuralları, güvenlik önceliği, yönetimin bağlılığı, güvenlik eğitimi, güvenlik liderliği, çalışanların teşviki, güvenlik iletişimi, güvenlik farkındalığı, çalışanların katılımı, güvenlik davranışları ve proses güvenliği. Boyutların seçiminde iki temel kriter belirlenmiştir. Birincisi araştırma yapılan kuruluşun özellikleri, yapılan iş ve eylemleri iken, ikincisi literatürde genel kabul görmüş olmasıdır.

\section{B- Güvenlik Kuralları}

Güvenlik kuralları “çalışanların güvenlik kurallarına yönelik düşüncelerini gösteren ve işini icra etmeye yönelik tutum ve davranışlarına yön veren bir boyut" olarak tanımlanmaktadır (Arpat, 2015: 46-47).

Literatürde çalışanların güvenlik kurallarına uygun hareket etmesi ile pozitif güvenlik kültürü arasındaki ilişkiler ortaya konulmaktadır. Bu bağlamda Şerifoğlu ve Sungur (2007: 14), çalışanların işveren tarafından konulan kural ve prosedürlere uyum ve katılım göstermesinin işyerinde pozitif güvenlik kültürünün yerleşmesine katkı sağlayacağını bildirmektedir.

Bu itibarla;

$\mathrm{H}_{1}$; Güvenlik kurallarının sağlıklı ve güvenli işyeri üzerinde olumlu etkisi vardır. 


\section{C- Güvenlik Önceliği}

Güvenlik önceliği; çalışma hızı ve verimlilik gibi işletmeye rekabet avantajı sağlayan hususlara bakılmaksızın işletme tarafından güvenliğin en önemli bir konu olarak kabul edilmesi anlamına gelmektedir (Naveh, Katz-Navon ve Stern, 2006: 121). Başka bir ifadeyle, yönetimin İSG'yi en öncelikli mesele olarak görüp 'önce insan, önce sağlı, önce iş güvenliği' anlayışında olması ve bunu net bir mesajla çalışanlarına ulaştırmasıdır (Şerifoğlu ve Sungur, 2007: 12). Yönetimin gündeminde yüksek öncelikli olmaya devam ettiği müddetçe, İSG konusunun işletmede önemli olduğu mesajı tüm çalışanlar tarafından algılanmış olur (Demirbilek, 2005: 159-191). Bir örgütün güvenlik konusuna verdiği önem, üç temel unsurla temsil edilmektedir, (1) Güvenlik Değerleri-Tavırları ve güvenlikten sorumlu üst yönetim tarafından ifade edilen değerler (sözle ya da önlemle), (2) Güvenlik Esasları-Eğitim gereklilikleri, el kitapları ve prosedürler, teçhizat bakımı gibi düzenlenmiş güvenlik esaslarına uygunluk ve (3) Uygunluk Dışındakiler-Düzenlemeler gerektirmese de şirket kaynaklarının (teçhizat, personel zamanı) tahsisinde güvenliğe verilen öncelik (Wiegmann, Von Thaden ve Gibbons, 2007: 122).

Güvenlik önceliği ile pozitif güvenlik kültürü arasında ilişki olduğu, literatürde yer almaktadır. Bottani, Monica ve Vignali (2009: 158), yönetimin İSG meselelerine üretim kadar önem vermemesini, çalışanların güvensiz davranış göstermelerinin ana sebebi olarak tanitmaktadir.

Bu itibarla;

$\mathrm{H}_{2}$; Güvenlik önceliğinin sağlıklı ve güvenli işyeri üzerinde olumlu etkisi vardır.

\section{D- Yönetimin (Güvenlik) Bağlılığı}

İş güvenliğine olan örgütsel bağlılık, örgüt üst yönetiminin karar alma sürecinde iş güvenliği konusuna ne ölçüde öncelik tanıdığını ve iş güvenliği için ne kadar kaynak ayırdığını ifade etmektedir (Wiegmann, Von Thaden ve Gibbons, 2007: 117).

Literatürde yönetimin bağlılığı ile güvenlik performansı arasındaki ilişkiler ortaya konulmaktadır. Yönetimin bağlılığ 1 ve güvenlik önlemlerini, güvenlik iklim faktörlerinden biri olarak tanıtan Vinodkumar ve Bhasi (2009) yönetimin bağlılığının güvenlik davranışları ile güvenlik performansını olumlu yönde etkilediğini bulmuştur. Mc Gonagle, Childressa, Walsh, ve Bauerle (2016) yönetimin taahhüdü ile küçük yaralanmalar arasında ise negatif yönde bir ilişsi bulmuştur. Çok tehlikeli işlerin yapıldığı küçük bir firmada Seixas, Crollard, Neitzel, Stover ve Dominguez (2016) tarafından yapılan araştırmada, yönetim güvenlik bağlılığının iş güvenliği performansını açık bir biçimde iyileştirdiği gözlemlemiştir. Ünal, Akbolat, Amarat ve Tilkilioğlu (2019) ve Gallagher, Underhill ve Rimmer (2003)'de, yönetimin bağlılığının güvenlik performansını olumlu yönde etkilediğini göstermektedir.

Bu itibarla;

$\mathrm{H}_{3}$; Yönetimin bağlılığının sağlıklı ve güvenli işyeri üzerinde olumlu etkisi vardır.

\section{E- Güvenlik Eğitimi}

Güvenlik eğitimi, çalışanların işlerini sağlıklı ve güvenli bir davranış içinde icra edecek yetkinliğe sahip olmalarını sağlamak üzere beceri, bilgi ve tutumlar geliştirmesi için kullanılan bir araçtır (Goldstein, 1986: 241). Sağlıklı ve güvenli işyeri ortamına sahip olmak isteyen kuruluşlar için güvenlik eğitimi en önemli güvenlik kültürü bileşenlerinden birisidir (Bayram, 2020). İnsan kaynakları bağlamında eğitimin temel amacı, çalışanların işle ilgili görevlere yönelik bilgi, beceri ve tutumların elde edilmesi ve geliştirilmesidir ve gerek 
çalışanlar ve gerekse örgütler için kısa ve uzun vadeli faydalara yol açabilecek en önemli potansiyel motivasyon araçlarından birisidir (Nassazi, 2013).

Literatürde güvenlik eğitiminin kaza ve yararlanmaların önlenmesine katkı sağladığını bildiren (Örneğin; Zohar, 1980; Guldenmund, 2000; Vinodkumar ve Bhasi, 2010; Burke, Sarpy, Smith-Crowe, Chan-Serafin, Salvador ve İslam, 2006; Kim, Rahim, Iranmanesh ve Foroughi; 2019) ve güvenlik performansı üzerinde olumlu etkisi olduğunu ortaya koyan pek çok çalışma (örneğin Lin ve Mills, 2001; Probst, 2004; Teo, Ling ve Chong, 2005; Mc Caughey, DelliFraine ve Erwin, 2015; Subramaniam, Shamsudin, Zin, Ramalu ve Hassan, 2016) bulunmaktadır.

Türkiye'de Özkan ve Arpat'1n (2016: 218) metal sektöründe İSG yönetim sistemi uygulamalarının güvenlik kültürü üzerine etkilerini incelediği araştırmada sadece güvenlik eğitimi üzerinde pozitif etkiler oluşturduğu, güvenlik önceliği, güvenlik kuralları, güvenli davranış, güvenlik farkındalığı, güvenlik iletişimi, güvenlik liderliği, güvenlik teşviki, yönetimin güvenlik bağlılığı boyutlarında negatif etkiler tespit edilmiştir. Özkan, Arpat ve Bingöl (2019: 414)'ün metal sektöründe yürüttüğü nitel araştırmada, çalışan perspektifinden sektörün en önemli sorunu güvenli olmayan çalışma ortamı olarak belirlenmiştir. Ancak çalışanlar güvenlik iyileştirmeleri için öncelikle güvenlik eğitimi ve bilinçlendirme faaliyetlerine vurgu yapmış, çalışma ortamının iyileştirilmesini ikincil bir eylem olarak gördüklerini ifade etmişlerdir.

Bu itibarla;

$\mathrm{H}_{4}$; Güvenlik eğitiminin sağlıklı ve güvenli işyeri üzerinde olumlu etkisi vardır.

\section{F- Güvenlik Liderliği}

Wu, Chen ve Li (2008: 312) tarafından güvenlik liderliği; lider ve takipçileri arasındaki etkileşim süreci olarak tanımlanmaktadır. Güvenlik liderliği sürecinin temel amacı; liderin çalışanların güvenlik davranışlarını olumlu yönde etkileyerek kuruluşun pozitif güvenlik kültürüne sahip olmasını sağlamaktır. Zira üst yönetimin liderliğinde ve taahhüdünde işyerlerinde pozitif güvenlik kültürü oluşturulmak suretiyle daha az iş kazası ve yaralanma vakası olması kaçınılmazdır (Bayram, 2018: 66).

Literatürde güvenlik liderliğinin pozitif güvenlik kültürü üzerindeki etkisini gösteren çalışmalar (örneğin; Wu, Chen ve Li, 2008; Yang, Wang, Chang, Guo ve Huang, 2010; Sonderstrap-Andersen, Carlsen, Kines, Bjorner ve Roepstorff, 2011; Arpat, 2015) mevcuttur. Ayrıca, Wu, Chen ve Li (2008) ve Yang, Wang, Chang, Guo ve Huang (2010) göre güvenlik liderliği ile güvenlik performansı arasında güvenlik kültürü aracılığıyla pozitif yönde bir ilişki bulunmaktadır. Bir başka deyişle güvenlik liderliği davranışı ile güvenlik kültürü arasında doğrudan, güvenlik liderliği davranışı ile güvenlik performansı arasında dolaylı bir ilişki bulunmaktadır.

Bu itibarla;

$\mathrm{H}_{5}$; Güvenlik liderliğinin sağlıklı ve güvenli işyeri üzerinde olumlu etkisi vardır.

\section{G- Güvenlik Teşviki}

Güvenlik teşviki, ödüllendirme sistemleri olarak da isimlendirilmektedir. Güvenlik teşviki, kuruluşların çalışanlarını tehlikesiz davranışlarının ödüllendirilmesi ya da tehlikeli davranışlarının cezalandırılması şeklinde olmaktadır. Bu bağlamda, kuruluşların çalışanların güvenli davranışlarının parasal teşvikler veya yöneticiler ve çalışma arkadaşları tarafından takdir ve övgü alma vb. ödüllendirme biçimleri ile teşvik edildiği, buna karşılık riskli ve 
güvensiz davranışlarının cezalandıılldığı sistemlere sahip olması gerekmektedir (Wiegmann, Von Thaden ve Gibbons, 2007: 118).

Daha önceki araştırmalar göstermiştir ki, şayet çalışanlar işyerlerindeki İSG standart, kural, prosedür ve düzenlemelere uygun hareket ettikleri taktirde, daha az kaza ve yaralanma olayı yaşanmaktadır (Subramaniam, Shamsudin, Zin, Ramalu ve Hassan, 2016: 231). Bu yüzden, örgütler iş güvenliği faaliyetlerine katılmaları ve iş güvenliği hedefleri, standartları ve prosedürlerine uymaları bağlamında çalışanları teşvik etmektedir (Andersson ve Paqarizi, 2016).

Bu itibarla;

$\mathrm{H}_{6}$; Güvenlik teşvikinin sağlıklı ve güvenli işyeri üzerinde olumlu etkisi vardır.

\section{Ğ- Güvenlik İletişimi}

Güvenlik iletişimi, kuruluş çalışanlarının işyerlerindeki İSG çalışmalarından haberdar olabilmesi anlamına gelmektedir (Arpat, 2015: 170). Bundan dolayı, kuruluş içinde sağlıklı bir şekilde işleyen "işletme içi”" bir iletişim süreci olmalıdır (Şerifoğlu ve Sungur, 2007: 12). Çalışanların geri bildirimine imkân veren öneri sistemleri en etkili güvenlik iletişimi unsurlarından biridir. Bunun dışında ödüllendirme sistemleri, kutlamalar, duyuru panoları, işletme içi yayınlar, intranet, yazılı prosedürler, toplantılar gibi pek çok iletişim araçları kullanılmaktadır (Şerifoğlu ve Sungur, 2007: 15).

Hoffman ve Stetzer (1998: 652), güvenlik iletişiminin, çalışanlar tarafından kazaların doğru yorumlanması ve iş kazalarından ders çıkarılması üzerinde olumlu etkisi olduğuna işaret etmektedir. Huang, Ho, Smith ve Chen (2006: 427) ise kaza olaylarında yöneticilerin suçlu arama tavırlarının çalışanların güvenlik risklerini saklama tavrına neden olduğunu bildirmektedir. Oysaki bunun yerine çalışanların destek ve katılımını sağlayacak örgütsel iletişim kanalları kullanılması halinde güvenlik performansı bundan olumlu bir şekilde etkilenecektir. Demirbilek (2008: 6), kuruluşun her seviyesindeki çalışanlar arasında samimi ve yaygın bir iletişim sisteminin olmasının, pozitif güvenlik kültürü oluşumuna katkı sağlayacağını bildirmektedir.

Bu itibarla;

$\mathrm{H}_{7}$; Güvenlik iletişiminin sağlıklı ve güvenli işyeri üzerinde olumlu etkisi vardır.

\section{H- Güvenlik Farkındalığı}

Güvenlik farkındalığı, güvenli tutum ve davranışların öncülüdür. Güvenlik farkındalığı güvenlik kültürü boyutlarından biridir (Arpat, 2015: 70). Güvenlik farkındalığını güvenlik iklimi boyutu olarak ele alan araştırmalar da bulunmaktadır (Lin, Tang, Miao, Wang, ve Wang, 2008: 1041). Şüphe yok ki çalışanların gerekli ISG farkındalığına sahip olması, iş kazası ve meslek hastalıklarını en aza indirecektir (Uçkun, Demir, Alkan ve Uçkun, 2017: 336). Çünkü kaza ve yaralanmayı önleme sorumluluklarının daha fazla farkına vardıklarında, çalışanlar sağlıklı ve güvenli bir işyeri oluşturulmasına daha fazla ilgi göstereceklerdir (Vecchio-Sadus ve Griffiths, 2004: 606). Bunun için, çalışanlar arasında sağlık ve güvenlik farkındalığını sağlayacak olumlu, eğlenceli ve örgütün tüm seviyeleri arasında iletişimi içeren ilgi çekici teşvik stratejileri uygulanmalıdır. Ancak düzenli ve sürekli iyileştirmeyi sağlayan bir İSG programı olmadıkça, güvenlik farkındalığının etkisi de kısa ömürlü olacaktır (Vecchio-Sadus ve Griffiths, 2004: 609).

Araştırmalar (Örneğin; Fung, Tam, Karen ve Ada, 2005; Dursun, 2012) iş kazasına uğrayan çalışanların güvenlik farkındalığının daha yüksek olduğunu ortaya koymaktadır. Meslek 
lisesi öğrencilerinin İSG’ye ilişkin farkındalıklarının güvenlik kültürü üzerindeki etkilerini araştırdıkları çalışmalarında Uçkun, Demir, Alkan ve Uçkun (2017), meslek lisesi öğrencilerinin İSG bilgi düzeylerinin sağlıklı ve güvenli çalışmaları bağlamında farkındalık yarattığını tespit etmişlerdir. Dursun ve Aytaç (2011) ise güvenlik farkındalığının güvenlik performansının sonucunu önceden tahmin ettiği sonucuna ulaşmıştır.

Bu itibarla;

$\mathrm{H}_{8}$; Güvenlik farkındalığının sağlıklı ve güvenli işyeri üzerinde olumlu etkisi vardır.

\section{İ- (Çalışanların) Güvenlik Katılımı}

Çalışanın güvenlik katılımı; bir çalışanın kişisel güvenliğine doğrudan katkısı olmayan ancak iş güvenliğinin sağlanmasını destekleyen bir ortamın geliştirilmesine yardımcı olan davranışları (örneğin; gönüllü olarak İSG faaliyetlerine katılmak, iş arkadaşlarına İSG konularında yardımcı olmak ve İSG toplantılarına katılmak gibi davranışlar) tanımlamak amacıyla kullanılmaktadır (Neal ve Griffin, 2006: 951; Vredenburg, 2002: 269). Bir başka ifadeyle güvenlik katılımı gönüllülük esası ile çalışanların kendi rollerinin de ötesinde güvenlik bağlamında ekstra rol davranışlarını ifade etmektedir (Clarke ve Ward, 2006: 1179; Mullen, Kelloway ve Teed, 2017: 409). Çalışanların işveren tarafindan konulan kural ve prosedürlere katılım göstermesi işyerinde pozitif güvenlik kültürünün yerleşmesine katkı sağlayacaktır (Şerifoğlu ve Sungur, 2007: 13).

Güvenlik katılımı ile iş kazası ve yaralanmalarda azalma arasında sağlam ampirik kanıtlar bulunmuştur (Neal ve Griffin, 2006; Christian, Bradley, Wallace ve Burke, 2009; Mullen, Kelloway ve Teed, 2017). Ministry of Science, Industry and Technology (2013) çalışmasında kaza ve meslek hastalıklarının ortaya çıkmasının önlenmesinde ISG tedbir veya programlarının özellikle katılımcı bir anlayışla tasarlanması halinde firmanın örgütsel ve çalışan düzeyinde faydalar sağlanabileceği vurgulanmaktadır. Şerifoğlu ve Sungur (2007: 1), kuruluş çalışanlarının tamamının katılımı sağlanarak İSG sürecinin yönetilmesini pozitif güvenlik kültürünün oluşturulmasında anahtar bir eylem olarak kabul etmektedir. Vinodkumar ve Bhasi (2009: 661), iş kazasına uğrayan işçilerin, daha az iş güvenliği önlemi aldığını ve iş güvenliği konularına düşük düzeyde katılım gösterdiklerini bildirmiştir.

Bu itibarla;

$\mathrm{H}_{9}$; Güvenlik katılımının sağlıklı ve güvenli işyeri üzerinde olumlu etkisi vardır.

\section{I- Güvenlik Davranışı}

İşyerlerinde operasyonel faaliyetlerin güvenli biçimde yapılması, çalışanların tutumlarının sağlıklı ve güvenli çalışmaya karşı olumlu olması ve nihayetinde bir bütün olarak çalışma eyleminin güvenli bir şekilde icra edilmesini ifade etmektedir. Güvenli davranışlar örgütlerin güvenlik performansının ölçülmesinde de öncü (leading) göstergeler olarak kullanılmaktadır. Çalışanların güvenlik uyumunu ve güvenlik katılımını da destekleyici bir etkiye sahiptir (Christian, Bradley, Wallace ve Burke, 2009: 1105).

İş kazaları, meslek hastalıkları ve maddi zararlara karşı son çare olan güvenli davranış eyleminin pozitif güvenlik kültürü üzerinde olumlu etkisi vardır (Fernández-Muñiz, MontesPeón ve Vázquez-Ordás, 2012; Olive, O’Connor ve Mannan, 2006; Bayram, 2020). Güvenlik davranışı ile güvenlik kültürü arasında anlamlı bir ilişki olduğu yazarlar (Clarke, 2006; Shang ve Lu, 2009; Dursun ve Aytaç, 2011) tarafından ortaya konulmuştur. Liu, Huang, Huang, Wang, Xiao ve Chen (2015), çalışanlar tarafından sağlıklı ve güvenli davranış sergilenmesinin iş kazası ve yaralanmaların sayısında azalma sağlanabileceğini ampirik olarak göstermiştir. Akalp ve Yamankaradeniz (2013) tarafından gerçekleştirilen çalışmada, 
işyerlerinde güvenli davranışların yaygınlaşması ile pozitif güvenlik kültürünün oluşacağı sonucuna varılmıştır. Japon petrokimya endüstrisinde yapılan başka bir araştırmaya göre, çalışanların güvenlik tutum ve davranışlarının, güvenlik kültürünün önemli bir indikatörü olduğu belirtilmektedir (Çakıt, Olak, Murata, Karwowski, Alreahili ve Marek, 2019: 15). Metal sektöründe güvenlik kültürü algısı ile iş güvenliği performansı arasındaki ilişkiyi incelediği araştırmasında Uslu (2014) güvenlik performansı ile güvenli davranış arasında pozitif yönlü bir ilişki bulmuştur.

Bu itibarla;

$\mathrm{H}_{10}$; Güvenli davranışın sağlıklı ve güvenli işyeri üzerinde olumlu etkisi vardır.

\section{J- Proses Güvenliği}

Arpat (2015: 62) proses güvenliğini, "Üretim süreçlerinin topyekûn güvenli olarak sürdürülmesi, yangın, patlama, kimyasalların yayılımı vb. gibi tehlikelerin neden olabileceği olayların önceden önlenerek can ve mal kayıplarının, çevre tahribatının önüne geçilmesi için uygulanan süreçler" olarak tanımlamaktadır. Özellikle çevre güvenliğini de etkileyen risk/tehdit unsurlarını barındıran işletmeler için, büyük öneme sahip bir boyuttur. Güvenlik yönetiminin önemli faaliyet alanlarından biridir. Bu bakımdan proses güvenliğinin bir performans göstergesi olarak ele alınması, bu eylemin de güvenlik üzerine önemli bir etkiye sahip olan üst yönetimlerin sorumluluğunda yerine getirilmesi gereklidir (Hopkins, 2007: 15). Üst yönetim faaliyetlerinin birden fazla güvenlik kültürü boyutunu oluşturması, önemli bir yönetim aktivitesi olan proses güvenliğinin de ayrı bir güvenlik kültürü boyutu olarak dikkate alınması ihtiyacını doğurmuştur (Carder ve Ragan, 2003: 159).

Bu itibarla;

$\mathrm{H}_{11}$; Proses güvenliğinin sağlıklı ve güvenli işyeri üzerinde olumlu etkisi vardır.

\section{II- ARAŞTIRMA MODELI}

Literatür araştırması sonucunda Şekil 1'de sunulan araştırma modeli tasarlanmıştır.

Şekil 1. Araştırma Modeli

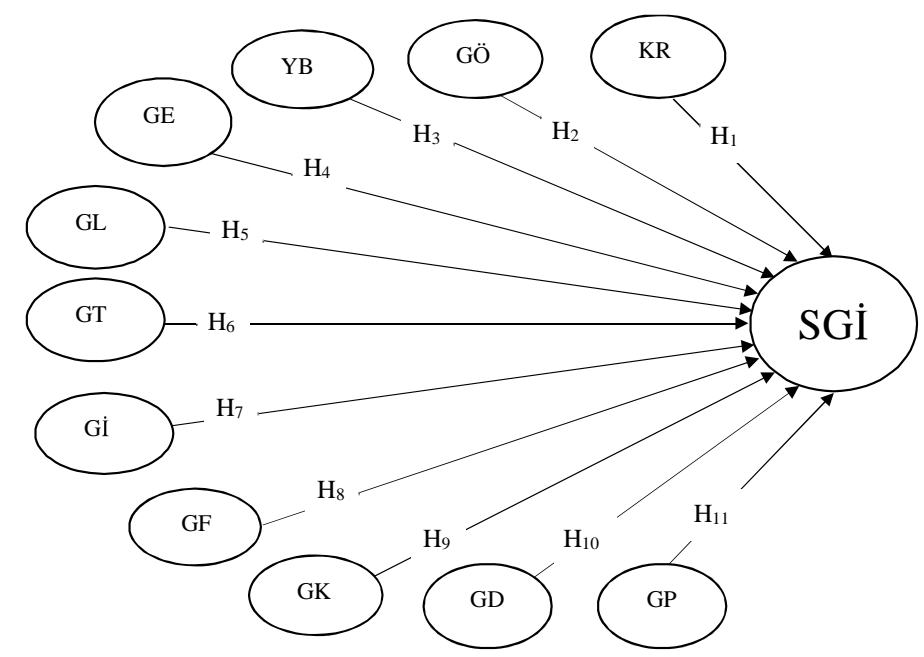

Not: YB, Yönetimin Bağlılığı; GD, Güvenlik davranışı; GE, Güvenlik Eğitimi; GF, Güvenlik Farkındalığı; Gİ, Güvenlik İletişimi; GK, Çalışan Katılımı; KR, Güvenlik Kuralları; GL, Güvenlik Liderliği; GÖ, Güvenlik Önceliği; GP, Proses güvenliği; GT, Güvenlik Teşviki. 


\section{III- YÖNTEM}

$\mathrm{Bu}$ araştırma, güvenlik kültürü bileşenlerinin sağlıklı ve güvenli bir işyeri oluşumuna katkısını belirlemeyi hedeflemektedir. Yazında gönderme yapılan güvenlik kültürü bileşeni sayısı 24'e kadar ulaşabilmektedir. Bu araştırma, anılan bileşenlerden en sık kullanılan 11 güvenlik kültürü bileşeni ile yürütülmüştür. Bileşenlerin seçiminde dikkate alınan diğer bir kriter ise tehlikeli/çok tehlikeli sektörler için kullanıma elverişli olmasıdır (proses güvenliği gibi).

Araştırma kesitsel tarama türünde, nicel araştırma yönteminde ve betimsel tarama deseninde icra edilmiştir. Araştırmada yanıt aranan problem cümlesi "Güvenlik kültürü ile betimlenen -sağlıklı ve güvenli bir işyeri- oluşumuna, güvenlik kültürü bileşenleri katkı sağlamakta mıdır?" olarak belirlenmiştir. Bu amaçla 11 hipotez belirlenmiş, sonuca ulaşmak üzere bu hipotez testlerinin bulguları yorumlanmış ve literatürel desteklerle bu yorumlara kanıtlar sunulmaya çalışılmıştır.

\section{A- Çalışma Grubu ve Veri Toplama}

Araştırma, bir büyükşehir belediyesinin su ve kanalizasyon işlerinde çalışan personeli ile yürütülmüştür. İşyeri tehlike sınıfları tebliğine göre bu faaliyetler "tehlikeli" sınıftadır. Uygulamanın yapıldığı grubun seçiminde, anılan bu işlerde fiili olarak çalışanlar tercih edilmiştir. Bu tercihin nedeni, doğrudan su ve kanalizasyon gibi operasyonel faaliyetlerde çalışanların (büro vb. işler gibi) diğer destek faaliyetlerde çalışanlara göre risk ve tehditlere daha fazla maruz kalmalarıdır. Araştırmanın çalışma grubu, anılan kriterlere uyan 480 belediye çalışanından oluşturulmuştur. Anket uygulaması için önce araştırmanın amaçları hakkında çalışanlara bilgi verilmiştir. Ardından formlar çalışanlara dağıtılmış ve bir hafta içinde tüm anket formları elden geri toplanmıştır. 25 anket yetersiz/geçersiz bulunmuş ve 455 kişilik bir veri seti ile analiz aşamasına geçilmiştir.

\section{B- Ölçekler}

$\mathrm{Bu}$ araştırma 11 boyuttan oluşmaktadır. Güvenlik kuralları (KR) boyutu beş maddeden oluşmakta olup boyutun ilk dört maddesi Cox ve Cheyne (2000: 124), son maddesi Mearns, Whitaker ve Flin (2003: 664) çalışmalarından uyarlanmıştır. Güvenlik önceliği (GÖ) boyutu için Cox ve Cheyne (2000: 116) tarafından geliştirilmiş olan üç maddeden oluşan ölçek kullanılmıştır. Yönetimin bağlılığ (YB) boyutu sekiz maddeden oluşmakta olup Mearns, Whitaker ve Flin (2003: 671), Fernández-Muñiz, Montes-Peón ve Vázquez-Ordás (2007: 632), Carder ve Ragan (2003: 160) ve Wu, Chen ve Li (2003: 313) çalışmalarından uyarlanmıştır. Güvenlik eğitimi (GE) boyutu dört maddeden oluşmakta olup Neal, Griffin ve Hart (2000: 103) ve Grote ve Kunzler (2000: 139) çalışmalarından uyarlanmıştır. Güvenlik liderliği (GL) boyutu için Wu, Lin ve Shiau (2010: 429) tarafindan geliştirilmiş olan dört maddeden oluşan ölçek kullanılmıştır. Güvenlik teşviği (GT) boyutu için Fernández-Muñiz, Montes-Peón ve Vázquez-Ordás (2007: 752) tarafından geliştirilmiş olan beş maddeden oluşan ölçek kullanılmıştır. Yönetimin iletişimi (GI) boyutu altı maddeden oluşmakta olup Bently ve Haslam (2001: 24), Cox ve Cheyne (2000: 118), Lin, Tang, Miao, Wang ve Wang, (2008: 1042) ile Glendon ve Litherland (2001: 169)'in çalışmalarından uyarlanmıştır. Güvenlik farkındalığı (GF) boyutu için Lin, Tang, Miao, Wang ve Wang, (2008: 1040) tarafından geliştirilmiş olan iki maddeden oluşan ölçek kullanılmıştır. Çalışan katılımı (GK) boyutu beş maddeden oluşmakta olup Mearns, Whitaker ve Flin (2003: 654), FernándezMuñiz, Montes-Peón ve Vázquez-Ordás (2007: 629), Carder ve Ragan (2003: 159) ve Vredenburgh (2002: 274) çalışmalarından uyarlanmıştır. Güvenlik davranışı (GD) boyutu için Neal, Griffin ve Hart (2000: 949) tarafından geliştirilmiş olan iki maddeli ölçek kullanılmıştır. Proses güvenliği (GP) boyutu için Carder ve Ragan (2003: 163) çalışmasından 
bir madde alınmıştır. Sağlıklı ve güvenli işyeri (SGİ) boyutunu ölçmek için yukarıda belirtilen 11 boyut altında yer alan 45 maddeden oluşan ikinci seviye (second order) bir yapı kullanılmıştır.

Araştırmanın başlangıç maddeleri boyutları ile birlikte Tablo 1.'de verilmiştir. Ölçeklerde 5'li Likert cevap bileşeni kullanılmıştır. Katılımcıların söz konusu değişkenlerle ilgili algılarını "1=Kesinlikle Katılmıyorum", "2=Katılmıyorum", "3=Ne Kat1lıyorum ne de Katılmıyorum", "4=Katılıyorum" ve " $5=$ Kesinlikle Katılıyorum" aralığında cevaplamaları istenmiştir.

Tablo 1. Araştırmanın Başlangıç Maddeleri ve İlgili Boyutları

\begin{tabular}{|c|c|c|}
\hline $\begin{array}{l}\text { Değişken } \\
\text { Kodu }\end{array}$ & Madde & Literatür \\
\hline KR & Güvenlik & \\
\hline KR1 & $\begin{array}{l}\text { İşi güvenle yapabilmek için bazı güvenlik kuralları ve prosedürlerinin } \\
\text { izlenmesine gerek yoktur. }\end{array}$ & \multirow{4}{*}{$\begin{array}{l}\text { Mearns, Whitake } \\
\text { ve Flin (2003) }\end{array}$} \\
\hline KR2 & $\begin{array}{l}\text { Bazı sağlık ve güvenlik kuralları ve prosedürleri pratikte uygulanabilir } \\
\text { değildir. }\end{array}$ & \\
\hline KR3 & Bazen, üretim uğruna güvenlik şartlarından ayrılmak gereklidir. & \\
\hline KR4 & Güvenlik kuralları çok katı, onlar olmadan daha iyi çalışabilirim. & \\
\hline KR5 & $\begin{array}{l}\text { Güvenlik ile ilgili kurallar, çalışanlar ile birlikte düzenli olarak gözden } \\
\text { geçirilir. }\end{array}$ & $\begin{array}{l}\text { Carder ve Ragan } \\
\text { (2003) }\end{array}$ \\
\hline GÖ & Güvenlik Önceliği & \\
\hline GÖ1 & Yönetim, çalışanların güvenliğine gerçekten büyük önem vermektedir. & \multirow{3}{*}{$\begin{array}{l}\text { Cox ve Cheyne } \\
\text { (2000) }\end{array}$} \\
\hline GÖ2 & Güvenlik konularına yüksek bir öncelik verildiğine inanmıyorum. & \\
\hline GÖ3 & Yönetim, güvenliği üretim ile eşit önemde görür. & \\
\hline YB & Yönetimin Bağlılığı & \\
\hline YB1 & Üst yönetim, çalışanların sağlığı ve güvenliğini gerçekten düşünür & $\begin{array}{l}\text { Mearns, Whitaker } \\
\text { ve Flin (2003) }\end{array}$ \\
\hline YB2 & Yöneticiler güvenlik konularında aktif ve görünür şekilde öncülük ederler. & \multirow{2}{*}{$\begin{array}{l}\text { Muniz, Peon ve } \\
\text { Ordas (2007) }\end{array}$} \\
\hline YB3 & $\begin{array}{l}\text { Yöneticiler çalışma koşullarını kontrol etmek veya çalışanlarla iletişimde } \\
\text { bulunmak için çalışma alanımı düzenli olarak ziyaret eder. }\end{array}$ & \\
\hline YB4 & $\begin{array}{l}\text { Çalışanlar, güvenlik amaç ve hedeflerinin düzenlenmesi çalışmalarına } \\
\text { katılırlar. }\end{array}$ & \multirow{2}{*}{$\begin{array}{l}\text { Carder ve Ragan } \\
\text { (2003) }\end{array}$} \\
\hline YB5 & Yönetim işletmenin başarısı kadar, güvenlik başarımıyla da ilgilidir. & \\
\hline YB6 & Yönetim çalışanlara düzenli olarak güvenlik hakkında bilgi verir. & \multirow{3}{*}{$\begin{array}{l}\text { Wu, Chen ve Li } \\
\text { (2008) }\end{array}$} \\
\hline YB7 & Yönetim, çalışanlar tarafından teklif edilen güvenlik önerilerini uygular. & \\
\hline YB8 & Güvenlik yönetimi uygulamaları sık sık kontrol edilir. & \\
\hline GE & Güvenlik Eğitimi & \\
\hline GE1 & Çalışanlar işyerinde sağlık ve güvenlik konularında kapsamlı eğitim alır. & \multirow{3}{*}{$\begin{array}{l}\text { Neal, Griffin ve } \\
\text { Hart (2000) }\end{array}$} \\
\hline GE2 & Güvenlik eğitimleri düzenli aralıklarla tekrar edilir/güncellenir. & \\
\hline GE3 & $\begin{array}{l}\text { İşyeri sağlık ve güvenlik eğitimi çalışanların işte karşılaştıkları çeşitli } \\
\text { durumları kapsar. }\end{array}$ & \\
\hline GE4 & Güvenli davranışı geliştirmek için yeterli derecede eğitim yapılmaktadır. & $\begin{array}{l}\text { Grote ve Kunzler } \\
(2000)\end{array}$ \\
\hline GL & Güvenlik Liderliği & \\
\hline GL1 & Çalışanlara iş güvenliği ile ilgili düzenli olarak rehberlik yapılır. & \multirow{4}{*}{$\begin{array}{l}\text { Wu, Lin ve Shiau } \\
\text { (2010) }\end{array}$} \\
\hline GL2 & İlk amirim çalışanların iş güvenliğini düzenli olarak gözlemler. & \\
\hline GL3 & $\begin{array}{l}\text { İlk amirim çalışanları güvenli davranışlar sergilemeleri için sık sık teşvik } \\
\text { eder. }\end{array}$ & \\
\hline GL4 & İlk amirim çalışanlarla güvenlik meselelerini sık sık konuşur. & \\
\hline
\end{tabular}


Tablo 1. Araştırmanın Başlangıç Maddeleri ve İlgili Boyutları (Devamı)

\begin{tabular}{|c|c|c|}
\hline $\begin{array}{l}\text { Değişken } \\
\text { Kodu }\end{array}$ & Madde & Literatür \\
\hline GT & Güvenlik Teşviki & \\
\hline GT1 & $\begin{array}{l}\text { (Koruyucu ekipmanların -düzgün- kullanımı gibi) Çalışanların ilke ve } \\
\text { prosedürlere uygun olarak davranmaları sık sık teşvik edilir. }\end{array}$ & \multirow{5}{*}{$\begin{array}{l}\text { Muniz, Peon ve } \\
\text { Ordas (2007) }\end{array}$} \\
\hline GT2 & $\begin{array}{l}\text { Üretim sürecindeki değişikliklerde, bundan etkilenen çalışanlara veya } \\
\text { temsilcilerine doğrudan danışılır. }\end{array}$ & \\
\hline GT3 & $\begin{array}{l}\text { Çalışanlardan gelen öneriler veya onlara danışılarak elde edilen bilgiler } \\
\text { çoğunlukla kabul edilir (benimsenir). }\end{array}$ & \\
\hline GT4 & $\begin{array}{l}\text { İş organizasyonunu etkileyen kararların alındığı, yönetim ve çalışanların } \\
\text { katıldığı toplantılar, periyodik olarak düzenlenir. }\end{array}$ & \\
\hline GT5 & $\begin{array}{l}\text { Farklı bölümlerden çalışanların oluş̧turduğu takımlar ile çalışma koşulları } \\
\text { ile ilgili spesifik problemler çözülmektedir. }\end{array}$ & \\
\hline Gi & Güvenlik İletişimi & \\
\hline Gİ1 & $\begin{array}{l}\text { Çalışanlar, güvenliğe aykırı davranışla karşılaştıklarında o kişiyi ikaz } \\
\text { ederler. }\end{array}$ & $\begin{array}{l}\text { Bently ve Haslam } \\
\text { (2001) }\end{array}$ \\
\hline Gí2 & İşyerimde beni etkileyen güvenlik meselelerinde iyi bir iletişim vardır. & \multirow{2}{*}{$\begin{array}{c}\text { Cox ve Cheyne } \\
\text { (2000) }\end{array}$} \\
\hline Gí3 & $\begin{array}{l}\text { İşletme yönetimi, güvenlik konularında "açık kapı politikası" (bir çalışanın } \\
\text { herhangi bir yönetici ile odasında görüşebilmesi) uygular. }\end{array}$ & \\
\hline Gİ4 & İş güvenliğine uyarak çalışmam nedeniyle “övgü/takdir” alıyorum. & \multirow[b]{2}{*}{$\begin{array}{l}\text { Glendon ve } \\
\text { Litherland (2001) }\end{array}$} \\
\hline Gí5 & $\begin{array}{l}\text { Çalışanların birbirini desteklemeleri ve birbirlerine dikkat etmeleri teşvik } \\
\text { edilir. }\end{array}$ & \\
\hline Gí6 & $\begin{array}{l}\text { İş arkadaşlarım genellikle işin emniyetli olarak nasıl yapılacağı konusunda } \\
\text { birbirlerine karş1lıklı tavsiyelerde bulunurlar. }\end{array}$ & $\begin{array}{c}\text { Lin, Tang, Miao, } \\
\text { Wang ve Wang, } \\
\text { (2008) }\end{array}$ \\
\hline GF & Güvenlik Farkındalığı & \multirow{3}{*}{$\begin{array}{c}\text { Lin, Tang, Miao, } \\
\text { Wang ve Wang, } \\
\text { (2008) }\end{array}$} \\
\hline GF1 & Güvenlik kurallarına her zaman uyarım. & \\
\hline GF2 & İşteyken en önemli şeyin güvenlik olduğunu düşünüyorum. & \\
\hline GK & Çalışan Katılımı & \\
\hline GK1 & $\begin{array}{l}\text { Çalışanlar yürüttükleri işlerin risk değerlendirmelerinde aktif olarak yer } \\
\text { alırlar. }\end{array}$ & $\begin{array}{c}\text { Mearns, Whitaker } \\
\text { ve Flin (2003) }\end{array}$ \\
\hline GK2 & Çalışanlar güvenlikle ilgili düzenlemelere uyarlar. & $\begin{array}{l}\text { Muniz, Peon ve } \\
\text { Ordas (2007) }\end{array}$ \\
\hline GK3 & Çalışanlar, güvenlik uygulamalarının geliştirilmesi çalışmalarına katılırlar. & $\begin{array}{c}\text { Carder ve Ragan } \\
\text { (2003) }\end{array}$ \\
\hline GK4 & İşletme yönetimi nihai kararları almadan önce çalışanların görüşlerini alır. & $\begin{array}{c}\text { Vredenburg } \\
(2002)\end{array}$ \\
\hline GK5 & Önemli güvenlik meselelerinde yönetimi bilgilendiririm. & $\begin{array}{l}\text { Cox ve Cheyne } \\
(2000)\end{array}$ \\
\hline GD & Güvenlik Davranışı & \multirow{3}{*}{$\begin{array}{c}\text { Neal, Griffin ve } \\
\text { Hart (2000)’tan } \\
\text { aktaran Dursun } \\
\text { (2012) }\end{array}$} \\
\hline GD1 & İşimi yaptığım esnada bütün gerekli güvenlik ekipmanlarını kullanırım. & \\
\hline GD2 & $\begin{array}{l}\text { İşyeri güvenliğinin iyileştirilmesine katkı sağlayacak görev ve aktiviteleri } \\
\text { gönüllü olarak yaparım. }\end{array}$ & \\
\hline PG & Proses Güvenliği & \\
\hline PG1 & Tehlike analizi ve üretim güvenliği konusunda yeterli düzeyde bilgi aldım. & $\begin{array}{c}\text { Carder ve Ragan } \\
\text { (2003) }\end{array}$ \\
\hline
\end{tabular}

\section{C- Veri Analizi}

Literatürden yola çıkarak geliştirilen Şekil 1'deki yapısal model ve araştırmanın hipotezleri Kısmi En Küçük Kareler- Yapısal Eşitlik Model (KEKK-YEM) yöntemiyle test edilmiştir. 
Bunun için toplanan veriler, DFA icra edilmek üzere Ringle, Wende ve Becker (2015) tarafından geliştirilen ve regresyon tabanlı yöntemlere göre avantajları olan (Gefen, 2000) Smart-PLS sürüm 3.2.7 yazılım programına girilmiştir. Smart PLS Versiyon 3.2.7 programında yapısal eşitlik modelleri (YEM) KEKK algoritması (PLS algorithm), önyükleme algoritması (bootstraping algorithm) ve körleme algoritması (blindfolding algorithm) olmak üzere ardışık üç ayrı algoritma aracılığıyla test edilmektedir. KEKK-YEM, Henseler, Ringle ve Sinkovics (2009) tarafından önerilen dış ölçüm modelinin ve iç yapısal modelin değerlendirilmesi olmak üzere iki aşamalı bir prosedürü içermektedir. Dahası, KEKK-YEM şu anda sosyal bilimler çalışmaları içinde çok değişkenli bir analiz için en uygun yöntem olarak bilinmekte ve tercih edilmektedir (Hussain, 2018: 10).

\section{III- BULGULAR}

\section{A- Demografik Bulgular}

Araştırmanın çalışma grubundaki kişilerin demografik özellikleri Tablo 2'de gösterilmiştir.

Tablo 2. Araştırma Katılımcılarının Demografik Özellikleri

\begin{tabular}{|c|c|c|c|c|c|}
\hline Cinsiyet & Sayı & $\%$ & Medeni Durum & Sayı & $\%$ \\
\hline Erkek & 348 & 80,4 & Evli & 378 & 83,1 \\
\hline Kadın & 85 & 18,7 & Bekâr & 56 & 12,3 \\
\hline Cevapsız & 22 & 4,8 & Cevapsiz & 21 & 4,6 \\
\hline Toplam & 455 & 100 & Toplam & 455 & 100 \\
\hline Eğitim Düzeyi & Sayı & $\%$ & Yaş & Sayı & $\%$ \\
\hline İlkokul & 88 & 19,3 & 29 yaş ve altı & 43 & 9,5 \\
\hline Ortaokul & 29 & 6,4 & $30-39$ & 153 & 33,6 \\
\hline Lise ve dengi & 104 & 22,9 & $40-49$ & 148 & 32,5 \\
\hline Üniversite & 196 & 43,1 & $50-59$ & 49 & 10,8 \\
\hline Diğer & 7 & 1,5 & 60 yaş ve üstü & 1 & 0,3 \\
\hline Cevapsız & 31 & 6,8 & Cevapsiz & 61 & 13,4 \\
\hline Toplam & 455 & 100 & Toplam & 455 & 100 \\
\hline
\end{tabular}

\section{B- Dış Ölçüm Modeli Bulguları}

Dış ölçüm modeli, gizil değişkenleri oluşturan gözlenen değişkenlerin yakınsak ve ayırıcı geçerliliği test edilerek değerlendirilmektedir. Smart PLS Versiyon 3.2.7 programında yakınsak ve ayırıcı geçerlilik KEKK algoritması (PLS Algorithm) çalıştırılarak test edilmektedir.

Dış ölçüm modelini değerlendirmesine geçmeden önce bağımsız değişkenler arasında çoklu doğrusal bağlantı probleminin varlığı araştırılmıştır. Çoklu bağlantı problemini araştırmak için bağımsız değişkenlere ait varyans büyütme faktörleri (VIF) değerlerine bakılmaktadır. $\mathrm{Bu}$ araştırmada kullanılan bağımsız değişkenlerin VIF değerleri KR2 hariç genel kesim eşiği aralığı olan 5'in altında bulunmuştur. Bu itibarla bundan sonraki analiz çalışmalarında KR2 değişkeni veri setinden çıkarılmıştır.

\section{i) Yakınsak Geçerliliğin Değerlendirilmesi}

Yakınsak geçerlilik için; (1) gizil değişkenlere yüklenen tüm gösterge yüklerinin eşik değer 0.600'1 (Hulland, 1999), (2) birleşik güvenirliklerin (CR) eşik değer 0.700’ü (Gefen, 2000) veya alternatif olarak Cronbach's Alpha'nın 0.650'ü aşması ve (3) her bir ölçek için açıklanan ortalama varyansın (AVE) eşik değer 0.500'ü aşması (Fornell ve Larcker, 1981) şarttır. Cronbach's Alpha ile karşılaştırıldığında, CR'nin gözlenen değişkenlerin standartlaştırılmış yüklerini koruduğu için iç tutarlılığı daha iyi değerlendirdiğine inanılmaktadır (Fornell ve Larker, 1981). Bu itibarla yakınsak geçerliliğin 
değerlendirilmesinde gösterge yükleri, bileşik güvenilirlik (CR) ve açılanan ortalama varyans (AVE) değerleri yeterli görülmektedir (Hair, Hult, Ringle ve Sarstedt, 2017).

İlk analizde gösterge yükleri 0.600'ün altında bulunan GÖ3, KR1, KR3 ve KR4 değişkenleri veri setinden çıkarılmıştır. Ayrıca, KR1, KR2, KR3 ve KR4 değişkenleri veri setinden çıkarıldığından, beş değişkene sahip KR ölçeğinde geriye sadece KR5 değişkeni kaldığından dolayı, "KR boyutu" veri setinden elimine edilmiş ve KEKK algoritması yeniden çalıştırılmıştır.

Tablo 3 'te görüleceği üzere kalan gösterge yükleri 0.600'ün üstünde bulunmuş ve birinci şart sağlanmıştır. CR değerleri 0.739 ile 1.000 arasında bulunarak ikinci şart da yerine gelmiştir. Son olarak AVE değerleri 0.541 ile 1.000 arasında bulunarak yakınsak geçerliliğin üçüncü şartı da sağlanmıştır. Dolayısıyla modeli oluşturan ölçeklerin yakınsak geçerliliği tatmin edici bulunmuştur.

Tablo 3. Ölçeklerin Yakınsak Geçerliliği

\begin{tabular}{|c|c|c|c|c|c|c|c|c|c|c|c|c|c|}
\hline & GF & GD & YB & Gi & GT & GL & GK & GÖ & GP & KR & GE & CR & AVE \\
\hline GF & & & & & & & & & & & & 0.904 & 0.824 \\
\hline GF1 & 0,919 & & & & & & & & & & & & \\
\hline GF2 & 0,896 & & & & & & & & & & & & \\
\hline GD & & & & & & & & & & & & $\mathbf{0 . 8 7 7}$ & 0.781 \\
\hline GD1 & & 0,876 & & & & & & & & & & & \\
\hline GD2 & & 0,892 & & & & & & & & & & & \\
\hline YB & & & & & & & & & & & & 0.907 & 0.550 \\
\hline YB1 & & & 0,773 & & & & & & & & & & \\
\hline YB2 & & & 0,781 & & & & & & & & & & \\
\hline YB3 & & & 0,658 & & & & & & & & & & \\
\hline YB4 & & & 0,685 & & & & & & & & & & \\
\hline YB5 & & & 0,695 & & & & & & & & & & \\
\hline YB6 & & & 0,761 & & & & & & & & & & \\
\hline YB7 & & & 0,790 & & & & & & & & & & \\
\hline YB8 & & & 0,779 & & & & & & & & & & \\
\hline GI & & & & & & & & & & & & 0.876 & 0.541 \\
\hline Gİ1 & & & & 0,687 & & & & & & & & & \\
\hline Gİ2 & & & & 0,770 & & & & & & & & & \\
\hline Gİ3 & & & & 0,765 & & & & & & & & & \\
\hline Gİ4 & & & & 0,656 & & & & & & & & & \\
\hline Gİ5 & & & & 0,805 & & & & & & & & & \\
\hline GÍ6 & & & & 0,722 & & & & & & & & & \\
\hline GT & & & & & & & & & & & & 0.874 & 0.583 \\
\hline GT1 & & & & & 0,739 & & & & & & & & \\
\hline GT2 & & & & & 0,836 & & & & & & & & \\
\hline GT3 & & & & & 0,805 & & & & & & & & \\
\hline GT4 & & & & & 0,753 & & & & & & & & \\
\hline GT5 & & & & & 0,676 & & & & & & & & \\
\hline GL & & & & & & & & & & & & 0.942 & 0.803 \\
\hline GL1 & & & & & & 0,892 & & & & & & & \\
\hline GL2 & & & & & & 0,931 & & & & & & & \\
\hline GL3 & & & & & & 0,899 & & & & & & & \\
\hline GL4 & & & & & & 0,860 & & & & & & & \\
\hline GK & & & & & & & & & & & & 0.875 & 0.587 \\
\hline GK1 & & & & & & & 0,834 & & & & & & \\
\hline GK2 & & & & & & & 0,812 & & & & & & \\
\hline GK3 & & & & & & & 0,849 & & & & & & \\
\hline GK4 & & & & & & & 0,659 & & & & & & \\
\hline GK5 & & & & & & & 0,652 & & & & & & \\
\hline
\end{tabular}


Tablo 3. Ölçeklerin Yakınsak Geçerliliği (Devamı)

\begin{tabular}{|c|c|c|c|c|c|c|c|c|c|c|c|c|c|}
\hline & GF & GD & YB & GI & GT & GL & GK & GÖ & GP & KR & GE & CR & AVE \\
\hline GÖ & & & & & & & & & & & & 0.739 & 0.596 \\
\hline GÖ1 & & & & & & & & 0,909 & & & & & \\
\hline GÖ2 & & & & & & & & 0,605 & & & & & \\
\hline${ }^{*}$ GÖ3 & & & & & & & & $-0,443$ & & & & & \\
\hline GP & & & & & & & & & & & & 1.000 & 1.000 \\
\hline GP1 & & & & & & & & & 1,000 & & & & \\
\hline${ }^{* * *} \mathrm{KR}$ & & & & & & & & & & & & & \\
\hline${ }^{*} \mathrm{KR} 1$ & & & & & & & & & & 0,185 & & & \\
\hline${ }^{*}$ KR3 & & & & & & & & & & 0,547 & & & \\
\hline${ }^{*}$ KR4 & & & & & & & & & & 0,388 & & & \\
\hline${ }^{* *}$ KR5 & & & & & & & & & & 0,732 & & & \\
\hline GT & & & & & & & & & & & & 0.880 & 0.648 \\
\hline GT1 & & & & & & & & & & & 0,828 & & \\
\hline GT2 & & & & & & & & & & & 0,844 & & \\
\hline GT3 & & & & & & & & & & & 0,737 & & \\
\hline GT4 & & & & & & & & & & & 0,808 & & \\
\hline
\end{tabular}

\section{ii) Ayırıcı Geçerliliğin Değerlendirilmesi}

Ayırıcı geçerliliğin sağlanması için Fornell ve Larcker (1981) bir gizil değişkenin AVE karekökünün diğer gizil değişkenler arasındaki korelasyonlardan daha büyük olmasını önermektedir. Ayırıcı geçerlik test sonuçları Tablo 4'te görülmektedir. Gizil değişkenlerin AVE kareköklerini gösteren çapraz değerlerin satır ve sütundaki diğer gizil değişkenlerin korelasyon değerlerinden daha büyük olması yeterli ayırıcı geçerliliğe işaret etmektedir. Bu itibarla ölçeklerin ayırt edici geçerliliği tatminkâr bulunmuştur.

Tablo 4. Ölçeklerin Ayırıcı Geçerliliği

\begin{tabular}{|c|c|c|c|c|c|c|c|c|c|c|}
\hline & GF & GD & YB & Gí & GT & GL & GK & GÖ & GP & GT \\
\hline GF & 0,908 & & & & & & & & & \\
\hline GD & 0,515 & 0,884 & & & & & & & & \\
\hline YB & 0,416 & 0,385 & 0,742 & & & & & & & \\
\hline Gí & 0,477 & 0,431 & 0,720 & 0,736 & & & & & & \\
\hline GT & 0,314 & 0,333 & 0,718 & 0,772 & 0,764 & & & & & \\
\hline GL & 0,338 & 0,355 & 0,691 & 0,644 & 0,682 & 0,896 & & & & \\
\hline GK & 0,543 & 0,558 & 0,694 & 0,718 & 0,651 & 0,583 & 0,766 & & & \\
\hline GÖ & 0,283 & 0,226 & 0,587 & 0,500 & 0,575 & 0,449 & 0,454 & 0,772 & & \\
\hline GP & 0,357 & 0,410 & 0,493 & 0,490 & 0,470 & 0,466 & 0,563 & 0,370 & 1,000 & \\
\hline GT & 0,396 & 0,328 & 0,667 & 0,595 & 0,553 & 0,496 & 0,582 & 0,447 & 0,519 & 0,805 \\
\hline
\end{tabular}

\section{C- İçsel Ölçüm Modeli Bulguları}

İçsel ölçüm modeli, Smart PLS Versiyon 3.2.7 programında sırasıyla KEKK algoritması (PLS Algorithm) ve önyükleme algoritması (Bootstrapping procedure) çalıştırılarak test edilmektedir. İçsel ölçüm modelinin değerlendirilmesi modelin tahmine dayalı alaka düzeyini ve yapılar arasındaki ilişkilerin gözlemlenmesini kapsamaktadır. Uyum İyiliği endeksi (SRMR), endojen yapıların belirlenme katsayısı $\left(\mathrm{R}^{2}\right)$, yol katsayısı ( $\beta$ değeri), ve Tistatistik değeri çalışmada iç yapısal modelin değerlendirilmesinde kullanılan ana standartlardır. 


\section{i) Modelin Uyum İyiliği}

Henseler, Ringle ve Sinkovics (2009) tarafından tanıtılan Standartlaştırılmış Ortalama Hataların Karekökü (SRMR) değeri, KEKK algoritması aracılığıyla modelin uyum iyiliğinin değerlendirilmesinde kullanılmaktadır. Schermelleh-Engel, Moosbrugger ve Müller (2003) 0.5 ila 1.00 arasında SRMR değerini iyi bir uyum değeri olarak önermektedir. Bu çalışma için SRMR değeri 0.99 olarak bulunarak modelin iyi bir uyum iyiliğine sahip olduğu sonucuna ulaşılmıştır.

\section{ii) Endojen Yapıların Belirlenme Katsayısı $\left(\mathbf{R}^{2}\right)$}

Modelin açıklama gücü endojen yapıların belirlenme katsayısı $\left(\mathrm{R}^{2}\right)$ gözlemlenerek test edilmektedir. Kabul edilebilir $\mathrm{R}^{2}$ değerleri 0.75 ise güçlü, 0.50 ise orta ve 0.25 ise zayıf olarak tanımlanmaktadır (Henseler, Ringle ve Sinkovics, 2009; Hair, Ringle ve Sarstedt, 2013). Analiz sonuçları, yapısal modelin güçlü bir açıklayıcı gücü olduğunu göstermektedir. Şekil 2'de görüleceği üzere, 10 gizil değişken (GF, GD, YB, Gİ, GT, GL, GK, GÖ, GP ve GT), ikinci sıra ölçek olan SGI'yi tam olarak $\left(\mathrm{R}^{2}=1.00\right)$ güçlü bir şekilde açıklamaktadır.

\section{iii) Hipotez Testi}

Hipotezler yol katsayısı ( $\beta$ değeri), ve T-istatistik değerleri aracılığıyla test edilmektedir. Hipotez testi için $T$ istatistiği kullanılmak suretiyle $\beta$ değeri yapılar arasındaki ilişkilerin istatistiksel olarak anlamlılık düzeyini doğrulaması amacıyla 500 alt örnekli bir önyükleme (bootstrapping) prosedürü gerçekleştirilmiştir. Önyükleme; yol katsayıları, Cronbach's Alpha, HTMT ve $\mathrm{R}^{2}$ değerleri gibi çeşitli KEKK-YEM sonuçlarının istatistiksel önemini test etmeye izin veren parametrik olmayan bir prosedürdür (Ringle Wende ve Becker, 2015).

Bulgular, KR gizil değişkeninin yakınsak geçerliliği sağlanamadığından $H_{1}$ hariç, yapılar arasında ilişkileri gösteren tüm hipotezleri $\left(\mathrm{H}_{2}, \mathrm{H}_{3}, \mathrm{H}_{4}, \mathrm{H}_{5}, \mathrm{H}_{6}, \mathrm{H}_{7}, \mathrm{H}_{8}, \mathrm{H}_{9}, \mathrm{H}_{10}\right.$ ve $\left.\mathrm{H}_{11}\right)$ güçlü bir şekilde desteklemektedir (Tablo 5). Dolayısıyla, güvenlik önceliğinin sağlıklı ve güvenli işyeri $(\beta=0.047, T=12.533, p=0.000)$, yönetimin bağlılığının sağlıklı ve güvenli işyeri $(\beta=0.255, T=31.528, p=0.000)$, güvenlik eğitiminin sağlılı ve güvenli işyeri $(\beta=0.125$, $\mathrm{T}=17.446, \mathrm{p}=0.000)$, güvenlik liderliğinin sağlıklı ve güvenli işyeri $(\beta=0.165 \mathrm{~T}=27.174$, $\mathrm{p}=0.000)$, güvenlik teşvikinin sağlıklı ve güvenli işyeri $(\beta=0.159 \mathrm{~T}=22.886, \mathrm{p}=0.000)$, güvenlik iletişiminin sağlıklı ve güvenli işyeri $(\beta=0.183, \mathrm{~T}=26.197, \mathrm{p}=0.000)$, güvenlik farkındalığının sağlıklı ve güvenli işyeri $(\beta=0.058 \mathrm{~T}=11.510, \mathrm{p}=0.000)$, güvenlik katılımının sağlıklı ve güvenli işyeri $(\beta=0,159, \mathrm{~T}=25,381, \mathrm{p}=0.000)$, güvenli davranışın sağlıklı ve güvenli işyeri $(\beta=0,053, T=10,250, p=0.000)$ ve güvenlik prosesinin sağlıklı ve güvenli işyeri $(\beta=0,040, T=18,158, p=0.000)$ üzerinde istatistiksel olarak anlamlı, doğrudan bir etkisi olduğu görülmüştür.

Tablo 5. Hipotez Testi

\begin{tabular}{|c|c|c|c|c|c|c|}
\hline Hipotez & Yol & $\begin{array}{c}\text { Original Sample } \\
(\mathrm{O})\end{array}$ & $\begin{array}{c}\text { Sample } \\
\text { Mean (M) }\end{array}$ & $\begin{array}{c}\text { Standard Deviation } \\
\text { (STDEV) }\end{array}$ & $\begin{array}{c}\text { T Statistics } \\
(|\mathrm{O} / \mathrm{STDEV}|)\end{array}$ & $\begin{array}{c}\mathbf{p} \\
\text { values }\end{array}$ \\
\hline$H_{1}$ & KR ->SGI & \multicolumn{5}{|c|}{ Yakınsak geçerlilik sağlanamadığı için hipotez testi yapılmamıştır. } \\
\hline $\mathrm{H}_{2}$ & GÖ -> SGİ & 0,047 & 0,048 & 0,004 & 12,533 & 0,000 \\
\hline $\mathrm{H}_{3}$ & YB -> SGİ & 0,255 & 0,255 & 0,008 & 31,528 & 0,000 \\
\hline$H_{4}$ & GE -> SGİ & 0,125 & 0,124 & 0,007 & 17,446 & 0,000 \\
\hline $\mathrm{H}_{5}$ & GL -> SGİ & 0,165 & 0,165 & 0,006 & 27,174 & 0,000 \\
\hline $\mathrm{H}_{6}$ & GT -> SGİ & 0,159 & 0,158 & 0,007 & 22,886 & 0,000 \\
\hline $\mathrm{H}_{7}$ & GI -> SGI & 0,183 & 0,183 & 0,007 & 26,197 & 0,000 \\
\hline$H_{8}$ & GF ->SGI & 0,058 & 0,058 & 0,005 & 11,510 & 0,000 \\
\hline$H_{9}$ & GK -> SGİ & 0,159 & 0,159 & 0,006 & 25,381 & 0,000 \\
\hline$H_{10}$ & GD -> SGİ & 0,053 & 0,053 & 0,005 & 10,250 & 0,000 \\
\hline$H_{11}$ & GP -> SGI & 0,040 & 0,040 & 0,002 & 18,158 & 0,000 \\
\hline
\end{tabular}


İçsel ölçüm modelinin değerlendirilmesi ile ilgili elde edilen bulguların şekilsel olarak ifadesi Şekil 2'de gösterilmektedir.

Şekil 2. Araştırma Modeli ve Bulguları

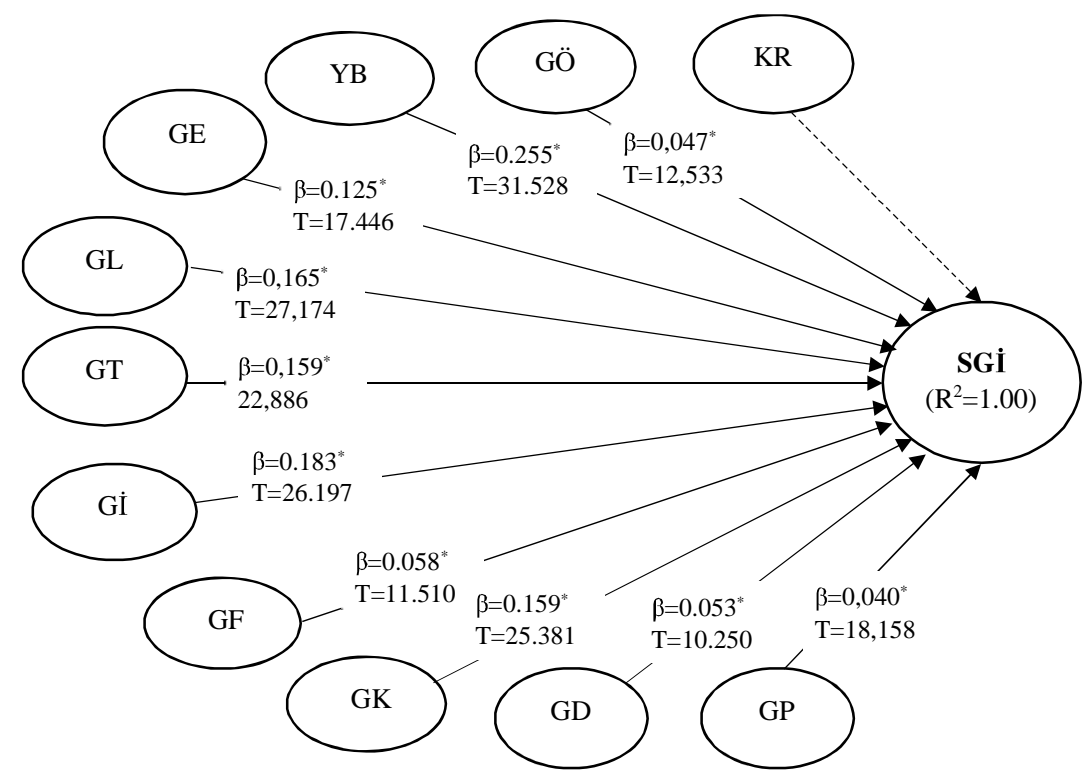

Not: ${ }^{*} \mathrm{p}<0.001$; Diz çizgiler doğrudan etkinin test edildiğini, kesikli çizgi yakınsak geçerlilik sağlanamadığı için yol testi yapılmadığını göstermektedir; YB, Yönetimin Bağlılığı; GD, Güvenlik davranışı; GE, Güvenlik Eğitimi; GF, Güvenlik Farkındalı̆̆ı; Gİ, Güvenlik İletişimi; GK, Çalışan Katılımı; KR, Güvenlik Kuralları; GL, Güvenlik Liderliği; GÖ, Güvenlik Önceliği; GP, Proses güvenliği; GT, Güvenlik Teşviki

\section{SONUÇ}

Araştırmada öngörülen 11 hipotezin 10'u $\left(\mathrm{H}_{2}, \mathrm{H}_{3}, \mathrm{H}_{4}, \mathrm{H}_{5}, \mathrm{H}_{6}, \mathrm{H}_{7}, \mathrm{H}_{8}, \mathrm{H}_{9}, \mathrm{H}_{10}\right.$ ve $\left.\mathrm{H}_{11}\right)$ test edilmiş ve bir ölçeğin (KR) yakınsak geçerliliği bulunamadığından $\mathrm{H}_{1}$ hipotezi test edilememiştir. Test edilen 10 hipotezin tamamının $\left(\mathrm{H}_{2}, \mathrm{H}_{3}, \mathrm{H}_{4}, \mathrm{H}_{5}, \mathrm{H}_{6}, \mathrm{H}_{7}, \mathrm{H}_{8}, \mathrm{H}_{9}, \mathrm{H}_{10}\right.$ ve $\left.\mathrm{H}_{11}\right)$ güçlü bir şekilde desteklendiği sonucuna ulaşılmıştır.

Güvenlik önceliğinin sağlıklı ve güvenli işyeri üzerinde istatistiksel olarak anlamlı doğrudan bir etkisi olduğu bulunmuştur. Bu ampirik bulgu yönetimin ISG meselelerine üretim kadar önem vermemesini çalışanların güvensiz davranış göstermelerinin ana sebebi olarak tanıtan Bottani, Monica ve Vignali (2009) çalışmasını desteklemektedir.

Yönetimin bağlılığının sağlıklı ve güvenli işyeri üzerinde istatistiksel olarak anlamlı doğrudan bir etkisi olduğu bulunmuştur. Bu ampirik bulgu, yönetimin bağlılığının güvenli davranış üzerinde olumlu etkisi olduğunu ortaya koyan Gallagher, Underhill ve Rimmer (2003), Vinodkumar ve Bhasi (2009), Seixas, Crollard, Neitzel, Stover ve Dominguez (2016) ve Ünal, Akbolat, Amarat ve Tilkilioğlu (2019) çalışmalarını desteklemektedir. Ayrıca, yönetimin taahhüdü ile küçük yaralanmalar arasında ise negatif yönde bir ilişki olan Mc Gonagle, Childressa, Walsh ve Bauerle (2016) çalışması ile uyumludur.

Güvenlik eğitiminin sağlıklı ve güvenli işyeri üzerinde istatistiksel olarak anlamlı doğrudan bir etkisi olduğu bulunmuştur. $\mathrm{Bu}$ ampirik bulguyu, güvenlik eğitiminin kaza ve yararlanmaların önlenmesine katkı sağladığını bildiren Zohar (1980), Guldenmund (2000), Vinodkumar ve Bhasi (2010), Burke, Sarpy, Smith-Crowe, Chan-Serafin, Salvador ve İslam (2006) ve Kim, AbdulRahim, Iranmanesh ve Foroughi (2019)'un çalışmaları 
desteklemektedir. Ayrıca, güvenlik eğitiminin güvenlik performansını olumlu yönde etkilediğini ortaya koyan Lin ve Mills (2001), Probst (2004), Teo, Ling ve Chong (2005), Mc Caughey, DelliFraine ve Erwin (2015), Subramaniam, Shamsudin, Zin, Ramalu ve Hassan (2016) çalışmaları ile de uyumludur.

Güvenlik liderliğinin sağlıklı ve güvenli işyeri üzerinde istatistiksel olarak anlamlı doğrudan bir etkisi olduğu bulunmuştur. $\mathrm{Bu}$ ampirik bulgu, güvenlik liderliğinin pozitif güvenlik kültürü üzerindeki etkisini ortaya koyan Wu, Chen ve Li (2008), Yang, Wang, Chang, Guo ve Huang (2010), Sonderstrap-Andersen, Carlsen, Kines, Bjorner ve Roepstorff (2011) ve Arpat (2015) çalışmaları ile tutarlıdır.

Güvenlik teşvikinin sağlıklı ve güvenli işyeri üzerinde istatistiksel olarak anlamlı doğrudan bir etkisi olduğu bulunmuştur. Bu ampirik bulgu Andersson ve Paqarizi (2016) söylemleri ile uyumludur. Çünkü Andersson ve Paqarizi (2016) örgütlerin İSG hedeflerine ulaşmak için çalışanların İSG faaliyetlerine katılması, İSG standart ve prosedürlerine uymaları bağlamında çalışanlarını teşvik ettiklerini bildirmektedir.

Güvenlik iletişiminin sağlıklı ve güvenli işyeri üzerinde istatistiksel olarak anlamlı doğrudan bir etkisi olduğu bulunmuştur. Bu bulgu, Nam (2019); Hoffman ve Stetzer (1998), Huang, Ho, Smith ve Chen (2006) söylemleri ile uyumludur. Bu bulguyla, kuruluşun her seviyesindeki çalışanlar arasında samimi ve yaygın bir iletişim sisteminin olması, pozitif güvenlik kültürü oluşumuna katkı sağlayacağını bildiren Demirbilek (2008) çalışması da ampirik olarak desteklenmiştir.

Güvenlik farkındalığının sağlıklı ve güvenli işyeri üzerinde istatistiksel olarak anlamlı doğrudan bir etkisi olduğu bulunmuştur. Bu ampirik bulgu, güvenlik farkındalığının güvenlik performansının sonucunu önceden tahmin ettiğini ortaya koyan Dursun ve Aytaç (2011) ve güvenlik eğitimi ve bilinçlendirme faaliyetlerinin ISSG'nin iyileştirilmesine katkı sağladığını vurgulayan Özkan, Arpat ve Bingöl (2019)'ün çalışmaları ile desteklenmektedir. Ayrıca farkındalığı yüksek olan meslek lisesi öğrencilerinin daha güvenli davranış sergilediğini ortaya koyan Uçkun, Demir, Alkan ve Uçkun (2017) ile Fung, Tam, Karen ve Ada (2005) ve Dursun (2012)'un bulguları ile de tutarlıdır.

Güvenlik katılımının sağlıklı ve güvenli işyeri üzerinde istatistiksel olarak anlamlı doğrudan bir etkisi olduğu bulunmuştur. $\mathrm{Bu}$ ampirik bulgu, güvenlik katılımı ile iş kazası ve yaralanmalarda azalma arasında sağlam ampirik kanıtlar bulan çalışmaları (Neal ve Griffin, 2006; Christian, Bradley, Wallace ve Burke, 2009; Mullen, Kelloway ve Teed, 2017) desteklemektedir. Başından iş kazası geçen işçilerin iş güvenliği konularına düşük düzeyde katılım gösterdiklerini bildiren Vinodkumar ve Bhasi (2009) çalışması ile uyumludur.

Güvenlik davranışının sağlıklı ve güvenli işyeri üzerinde istatistiksel olarak anlamlı doğrudan bir etkisi olduğu bulunmuştur. Bu bulgu, çalışanlar tarafından sağlıklı ve güvenli davranış sergilenmesinin güvenlik performansında iyileşme sağlanabileceğini ortaya koyan Uslu (2014) ve Liu, Huang, Huang, Wang, Xiao ve Chen (2015) çalışmasını desteklemektedir. Ayrıca çalışanların güvenli davranış göstermelerinin pozitif güvenlik kültürü üzerinde olumlu etkisi olduğunu ortaya koyan çalışmalar (Fernández-Muñiz, Montes-Peón ve Vázquez-Ordás, 2012; Akalp ve Yamankaradeniz, 2013; Olive, O’Connor ve Mannan, 2006; Bayram, 2020; Çakıt, Olak, Murata, Karwowski, Alreahili ve Marek, 2019) ile de uyumludur.

Proses güvenliğinin sağlıklı ve güvenli işyeri üzerinde istatistiksel olarak anlamlı doğrudan bir etkisi olduğu bulunmuştur. Bu bulgu da Carder ve Ragan (2003)'ın çalışması ile uyumludur. 
İş güvenliği meselelerine verdiği önceliğe bağlı olarak üst yönetimin güvenliği önceleyen bir liderlik sergilemesi ve ara yönetim kademeleri ile çalışanlar arasında da güvenlik liderliğini teşvik edici eylemlerde bulunması; güvenlik liderliğinin etkisini ve faydalarını arttırmada önemli bir rol oynayabilir. Bu çerçevede örgütün her kademesinde var olan (etkili ve güvenliğe motive olmuş) güvenlik liderliğinin, sağlıklı ve güvenli bir işyeri oluşumuna önemli bir katkı sağlayacağı söylenebilir. Bu tip bir liderlik anlayışı ile olumlu güvenlik iletişimine, güvenlik farkındalığına, güvenlik uyumuna, güvenli davranışa ve güvenlik faaliyetlerine katılıma dönük iyileştirmeler elde edilebilir. Böylece güvenlik kültürü iyileştirilebilir ve bu yolla örgüt kültürünün de geliştirilmesine yönelik pozitif dışsallıklar sağlanabilir.

Kuruluşlar birbirlerine rekabet avantajı sağlamak için alınan her ticari kararda kalite, maliyet ve getiri gibi birbirleriyle yarışan birçok öncelik bulunmaktadır. Ancak koşullar ne olursa olsun, üst yönetim güvenlik konusuna birincil önceliği tanımalıdır. Böylece üst yönetimin baştan aşağı örgütün her yerinde iş güvenliği konusuna güçlü bir liderlik ve sıkı sıkıya bağlılık gösterdiği anlaşılabilir. Yöneticiler güvenlik konusuna ne kadar eğilirlerse, çalışanlarının güvenlik davranışlarını ödüllendirme ve onlara maksimum güvenlik ile iş yapabilmeleri için gerekli olan bilgileri aktarmaları da o denli olası olacak ve böylelikle çalışanlar işlerini güvenli bir şekilde yapabilmek için daha az kaygı yaşamış olacaklardır.

Araştırma bulgularının tüm sektörlere ve tehlike sınıflarına genellenebilmesi mümkün değildir. Bu tip bir genelleme için, bu konuda daha fazla araştırma yapılması gereklidir. Bu araştırmanın bulguları, sadece bir büyükşehir belediyesinin su ve kanalizasyon işi çalışanlarından elde edilmiştir. $\mathrm{Bu}$ nedenle bulguların, sadece bu tip işyerleri için genellenebilmesi mümkündür. Bu durum, araştırmanın bir kısıtı olarak ön plana çıkmaktadır.

Bundan sonraki araştırmalarda, güvenlik kültürü ve boyutlarının sağlıklı ve güvenli işyeri oluşturma üzerine etkisi, farklı sektörlerde ve tehlike sınıfları üzerinde de tekrarlanabilir. Bu araştırmalar, güvenlik kültürünü açıklayan farklı boyutların tercih edilmesiyle de yürütülebilir. Dahası, sağlıklı ve güvenli bir işyeri oluşumunda, güvenlik kültürünün sosyal ve bilişsel bir aracı olan güvenlik iklimi veya güvenlik performansının etkisi üzerine araştırmaların yürütülmesi de mümkündür.

\section{Kaynakça}

Akalp, G. ve Yamankaradeniz, N. (2013). İşletmelerde Güvenlik Kültürünün Oluşumunda Yönetimin Rolü ve Önemi. Sosyal Güvenlik Dergisi. 3.2. 96-109.

Arcury, T. A., Arnold, T. J., Mora, D. C., Sandberg, J. C., Daniel, S. S., Wiggins, M. F., ve Quandt, S. A. (2019). "Be careful!” Perceptions of Work-Safety Culture Among Hired Latinx Child Farmworkers in North Carolina. American Journal of Industrial Medicine. 62.12. 1091-1102. doi: 10.1002/ajim.23045.

Andersson V. ve Paqarizi I. (2016). Safety Motivation System: A Qualitative Study Regarding What Creates Safety Motivation in a Company That Operates in a Hazardous Business (unpublished master's thesis). Linköping: Linköping University.
Arpat, B. (2015). Işs Güvenliği Kültürünün IS Kazalarına Etkileri: Metal Sektörü - Denizli İli Örneği. Yayınlanmamış Doktora Tezi. Sakarya Üniversitesi, Sosyal Bilimler Enstitüsü, ÇEEİ, Sakarya.

Atan, M., Cam, E., Çelik, E., Arslan, B. Y. ve Eravc1, D. B. (2017). Türkiye'de İş Sağlığı ve Güvenliği Algısı, ÇASGEM Araştırma Raporu. Ankara: Uzerler Matbaacılık.

Bayram, M. (2018). The Management Commitment to OHS. Employee Satisfaction and Safety Performance: An Empirical Study. International Journal of Latest Engineering and Management Research. 3.7. 63-71.

Bayram, M. (2020). Factors Affecting Employee Safety Productivity: An Empirical Study in an OHSAS 18001-certified Organization. International Journal of Occupational Safety and Ergonomics. doi: 10.1080/10803548.2020. 1739892 
Bently, T. A. ve Haslam, R. A. (2001). A Comparison of Safety Practices Used by Managers of High and Low Accident Rate Postal Delivery Offices. Safety Science. 37(1). 19-37.

Bottani, E., Monica, L. ve Vignali G. (2009). Safety Management Systems Performance Differences Between Adopters and NonAdopters. Safety Science. 47. 155-162. doi: 10.1016/j.ssci.2008.05.001

Burke, M. J., Sarpy, S. A., Smith-Crowe, K., Chan-Serafin, S., Salvador, R. O. Ve İslam, G. (2006). Relative Effectiveness of Worker Safety and Health Training Methods. American Journal of Public Health. 96.2. 315-324.

Carder, B. ve Ragan, P.W. (2003). A Surveybased System for Safety Measurement and Improvement. Journal of Safety Research. 34. 157-165.

Christian, M. S., Bradley, J. C., Wallace, J. C. ve Burke, M. J. (2009). Workplace Safety: A MetaAnalysis of the Roles of Person and Situation Factors. Journal of Applied Psychology. 94.5. 1103-1127.

Clarke, S. (2006). Safety Climate in an Automobile Manufacturing Plant. Personnel Review. 35.4. 413-430.

Clarke, S. ve Ward, K. (2006). The Role of Leader Influence Tactics and Safety Climate in Engaging Employee's Safety Participation. Risk Analysis. 26. 1175-1185.

Cox, S. J. ve Cheyne, A. J. T. (2000). Assessing Safety Culture in Offshore Environments. Safety Science. 34. 111-129.

Çakıt, E., Olak, A.J., Murata, A., Karwowski, W., Alreahili, O. \& Marek, T. (2019). Assessment of the Perceived Safety Culture in the Petrochemical Industry in Japan: A Crosssectional Study. doi: 10.1371/journal.pone.0226416

Demirbilek, T. (2005). Işs Güvenliği Kültürü. İzmir: Legal Yayınları.

Demirbilek, T. (2008). İşletmelerde İş Güvenliği Kültürünün Geliştirilmesi. Çalışma Ortamı Dergisi. 96. 5-7.

Dursun, S. (2012). İş Güvenliği Kültürü Kavram, Modeller, Uygulama. İstanbul: Beta Yayınevi.
Dursun, S. ve Aytaç, S. (2011). The Effect of Safety Culture on Safety in an Organizational Structure: A Case Study in Turkey. In $10^{\text {th }}$ International Symposium on Human Factors in Organisational Design and Management (ODAM 2011). 4-6.

Fernández-Muñiz, Montes-Peón ve VázquezOrdás (2007). Safety Culture: Analysis of the Casual Relationships Between ts Key Dimensions. Journal of Safety Research. 38. 627-641.

Fernández-Muñiz, B. Montes-Peón, J. M. ve Vázquez-Ordás, C. J. (2012). Safety Climate in OHSAS 18001-Certified Organisations: Antecedents and Consequences of Safety Behaviour. Accident Analysis and Prevention. 45. 745-758. doi: 10.1016/j.aap.2011.10.002.

Fornel, C. ve Larker, D. F. (1981). Evaluating Structural Equation Models with unobservable Variables and Measurement error. Journal of Marketing Research. 18.1. 39.50. [https://www.jstor.org/stable/3151312?seq=2\#p age_scan_tab_contents]. (Erişim: 20 Aralık 2020).

Fung, I. W. H., Tam, C. M., Karen C. F. T. Ada S. K. M. (2005). Safety Culture Divergences Among Management. Supervisory and Worker Groups in Hong Kong Construction Industry. Science Direct. International Journal of Project Management. 23. 504-512.

Gallagher, C., Underhill, E. ve Rimmer, M. (2003). Occupational Safety and Health Management Systems in Australia: Barriers to Success. Policy And Practice in Health And Safety. 1.2. 67-81. doi: 10.1080/14774003.2003.11667637

Gefen, D. (2000). Structural Equation Modeling and Regression: Guidelines for Research Practice Structural. Struct. Equ. Model. 4-7.

Glendon, A. I. ve Litherland, D. K. (2001). Safety Climate Factors, Group Differences and Safety Behaviour. Road Construction. Safety Science. 39. 157-188.

Goldstein, I. L. (1986). Training in Work Organisations. Annual Review of Psychology. 31. 229-272.

Grote, G. ve Künzler, C. (2000). Diagnosis of Safety Culture in Safety Management Audits. Safety Science. 34.131-150. 
Guldenmund, F. (2010). Understanding and Exploring Safety Culture. Uitgeverij BOXPress Oisterwijk.

Guldenmund, F. (2000). The Nature of Safety Culture: A Review of Theory and Research. Safety Science. 34. 215-257.

Hair J. F., Ringle C. M. ve Sarstedt M. (2013). Partial Least Squares Structural Equation Modeling: Rigorous Applications. Better Results and Higher Acceptance. Long Range Plann. 46. 1-12.

Hair, J. F., Hult, G. T. M., Ringle, C. M. ve Sarstedt, M. (2017). A Primer on Partial Least Squares Structural Equation Modelling (PLSSEM). Los Angeles, London. New Delhi, Singapore. Washington DC: Sage.

Henseler, J. Ringle, C. M. ve Sinkovics, R. (2009). The Use of Partial Least Squares Path Modeling in International Marketing. Advances in International Marketing. 20. 277-319.

Hofmann, D. A. ve Stetzer, A. (1998). The Role of Safety Climate and Communication in Accident Interpretation: Implications For Learning From Negative Events. Academy of Management Journal. 41.6. 644-657.

Hopkins, A. (2007). Thinking About Process Safety Indicators. Safety Science. 47.4. 460-465. doi: 10.1016/j.ssci.2007.12.006

Huang, Y. H., Ho, M., Smith, G. S. ve Chen, P. Y. (2006). Safety Climate and Selfreported Injury: Assesing the Mediating Role of Employee Safety Control. Accident Analysis and Prevention. 38.3. 425-433.

Hulland, J. (1999). Use of Partial Least Squares (PLS) in Strategic Management Research: A Review of Four Recent Studies. Strategic Management Journal. 20.2. 195-204.

Hussain, S. Fangwei, Z. Siddiqi A. Ali, Z. ve Shabbir, M. S. (2018). Structural Equation Model for Evaluating Factors Affecting Quality of Social Infrastructure Projects. Sustainability. 10. 1-25. doi: 10.3390/su10051415

Kim, N. K., Rahim, N. F. A., Iranmanesh, M. ve Foroughi, B. (2019). The Role of the Safety Climate in the Successful Implementation of Safety Management Systems. Safety Science. 118. 48-56.
Lin, J. ve Mills, A. (2001). Measuring The Occupational Health and Safety Performance of Construction Companies in Australia. Facilities. 19(3/4). 131-139. doi: 10.1108/02632770110 381676

Lin, S. H., Tang, W. J., Miao, J. Y., Wang, Z. M. ve Wang, P. X. (2008). Safety Climate Measurement at Workplace in China: A Validity and Reliability Assesment. Safety Science. 46.7. 1037-1046.

Liu, X., Huang, G., Huang, H., Wang, S., Xiao, Y. ve Chen, W. (2015). Safety Climate, Safety Behavior, and Worker Injuries in the Chinese Manufacturing Industry. Safety Science. 78. 173-178.

Mc Caughey, D., DelliFraine, J. ve Erwin, C. O. (2015). Best Practices to Promote Occupational Safety and Satisfaction: A comparison of Three North American Hospitals. In International Best Practices in Health Care Management. Emerald Group Publishing Limited.

Mc Gonagle, A. K. Childressa, N. M. Walsh, B. M. ve Bauerle, T. J. (2016). Can Civility Norms Boost Positive Effects of Management Commitment to Safety? The Journal of Psychology. 50.5. 591-605.

Mearns, K., Whitaker, S. M. ve Flin, R. (2003). Safety Climate, Safety Management Practice and Safety Performance in Offshore Environments. Safety Science. 41.8. 641-680.

Ministry of Science, Industry and Technology (2013). The Link Between Productivity and Health and Safety at Work, Background Research Paper, Ankara: Ministry of Science, Industry and Technology Directorate General for Productivity (Turkey). [http://www.hesapro.org/files/Background_Res earch.pdf]. (Erişim: 3 Mart 2020).

Mullen, J., Kelloway, E. K. ve Teed, M. (2017). Employer Safety Obligations, Transformational Leadership and Their Interactive Effects on Employee Safety Performance. Safety Science. 91. 405-412.

Nam, D. (2019). IŞ Güvenliği Kültürü ve Güvenli Davranış Arasındaki İlişki: Gemi İnşa Sanayinde Bir Araşstırma. Yayınlanmamış Doktora Tezi. Sakarya Üniversitesi, Sosyal Bilimler Enstitüsü, ÇEEİ. Sakarya.

Nassazi, A. (2013). Effects of Training on Employee Performance: Evidence from Uganda, Dissertation, Vaasa: Vaasan Ammattikorkeakoulu University of Applied Sciences. 
Naveh, E., Katz-Navon, T. ve Stern, Z. (2006). Readiness to Report Medical Treatment Errors: The Effects of Safety Procedures. Safety Information and Priority of Safety. Medical Care. 44.2. 117-123.

Neal, A. ve Griffin, M. A. (2006). A Study of the Lagged Relationships Among Safety Climate. Safety Motivation, Safety Behavior and Accidents at the Individual and Group Levels. Journal of Applied Psychology. 91.4. 946-953.

Neal, A., Griffin, M. A. ve Hart, P. M. (2000). The Impact of Organizational Climate on Safety Climate and Individual Behaviour. Safety Science. 34. 99-109.

Olive, C., O’Connor, T.M. ve Mannan, M.S. (2006). Relationship of Safety Culture and Process Safet. Journal of Hazardous Materials. 130. 133-140.

Özkan, Y. ve Arpat, B. (2016). İşletmelerde Uygulanan Yönetim Sistemlerinin Güvenlik Kültürü Üzerine Etkisi: Denizli İli - Metal Sektörü Örneği. Siyaset, Yönetim ve Ekonomi Araştırmaları Dergisi. 4.4. 195-221.

Özkan, Y., Arpat, B. ve Bingöl, U. (2019). Çalışanların Perspektifinden İş Sağlığı ve Güvenliği Sorunları ile Çözüm Önerileri: Türk Metal Sektörüne İlişkin Demografik bir Durum Çalışması. 2. International Conference on Empirical Economics and Social Sciences. 2022.Haziran 2019. Balıkesir. 400-409.

Özkan, T. ve Lajunen, T. (2003). Güvenlik Kültürü ve İklimi. Pivolka. 2.10. 3-4.

Pınar, T. (2015). Sağliklı ve Güvenli Bir İşyeri Oluşturmak. (Guidotti, T. L. (2014) Creating a Safety and Healthy Workplace, ICOH'tan çeviri). Hacettepe Üniversitesi.

Probst, T. M. (2004). Safety and Insecurity: Exploring the Moderating Effect of Organizational Safety Climate. Journal of Occupational Health Psychology. 9.1. 3-10. doi: 10.1037/1076-8998.9.1.3

Ringle, C. M., Wende, S. ve Becker, J. M. (2015). SmartPLS 3. Boenningstedt: SmartPLS GmbH. [http://www.smartpls.com]. (Erişim: 22 Aralık 2020).

Seixas, N. S., Crollard, A., Neitzel, R., Stover, B. ve Dominguez, C. (2016). Intervening at the Bottom: Can a Health and Safety Committee Intervention Influence Management Commitment? Policy and Practice in Health and Safety. 11.1. 61-78.
Schermelleh-Engel, K., Moosbrugger, H. ve Müller, H. (2003). Evaluating the Fit of Structural Equation Models: Tests of Significance and Descriptive Goodness-Of-Fit Measures. Methods of Psychological Research Online. 8.2. 23-74.

Shang, K. C. ve Lu, C. S. (2009). Effects of Safety Climate on Perceptions of Safety Performance in Container Terminal Operations. Transport Reviews. 29.1. 1.19. doi: 10.1080/01441640802264943

Sonderstrap-Andersen Hans H. K., Carlsen, K., Kines, P., Bjorner, J. B. ve Roepstorff C. (2011). Exploring the Relationship Between Leadership Style and Safety Climate in A Large Scale Danish Cross-Sectional Study. Safety Science Monitor. 1.15. 1-9.

Subramaniam, C., Shamsudin, F. M., Zin, M. L. M., Ramalu, S. S. ve Hassan, Z. (2016). Safety Management Practices and Safety Compliance in Small Medium Enterprises: Mediating Role of Safety Participation, Asia-Pacific Journal of Business Administration. 8.3. 226-244. doi:10.1108/APJBA-02-2016-0029

Şerifoğlu, U. K. ve Sungur, E. (2007). İşletmelerde Sağllk ve Güvenlik Kültürünün Oluşturulmasi; Tepe Yönetimin Rolü ve Kurum İçi İletişim Olanaklarının Kullanımı. Yönetim Dergisi. 18.58. 1-17.

Teo, E. A. L., Ling, F. Y. Y. ve Chong, A. F. W. (2005). Framework for Project Managers to Manage Construction Safety. International Journal of Project Management. 23.4. 329-341. doi: 10.1016/j.ijproman.2004

Uçkun, C. G., Demir, B., Alkan, S. ve Uçkun, S. (2017). Meslek Liselerinde Okuyan Öğrencilerin İş Güvenliği Farkındalığı. International Journal of Academic Value Studies. 3.15. 328-347. doi: 10.23929/javs.561

Uslu, V. (2014). Işsletmelerde İş Güvenliği Performansı ve isş Güvenliği Algılamaları Arasındaki İlişki: Eskişehir İli Metal Sektöründe Bir Araştırma. Osmangazi Üniversitesi. Sosyal Bilimler Enstitüsü. Yayınlanmamış Yüksek Lisans Tezi. Eskişehir.

Uttal, B. (1983). The Corporate Culture Vultures. Fortune Magazine October-17.

Ünal, Ö., Akbolat, M. Amarat, M. ve Tilkilioğlu, S. (2019). The Role of the Human Factor in Occupational Safety and Health Performance. International Journal of Occupational Safety and Ergonomics. doi: 10.1080/10803548.2018. 1554932 
Vecchio-Sadus, A. M. ve Griffiths, S. (2004). Marketing Strategies for Enhancing Safety Culture. Safety Science. 42.7. 601-619.

Vinodkumar, M. N. ve M. Bhasi (2009). Safety Climate Factors and its Relationship with Accidents and Personal Attributes in the Chemical Industry. Safety Science. 47. 659-667.

Vredenburgh A. (2002). Organizational Safety: Which Management Practices are Most Effective in Reducing Employee Injury Rates? Journal of Safety Research. 33. 259-276.

Wiegmann, D. A., Von Thaden, T. L. ve Gibbons, A. M. (2007). A Review of Safety Culture Theory and its Potential Application to Traffic Safety. In: Improving Traffic Safety Culture in the United States: The Journey Forward, AAA Found Traffic Safety. 113-129.

Wu, T.C., Chen, C. H. ve Li, C. C. (2008). A Correlation Among Safety Leadership. Safety Climate and Safety Performance. Journal of Loss Prevention in the Process Industries. 21.3. 307-318.

Wu, T. C., Lin, C. H. ve Shiau, S. Y. (2010). Predicting Safety Culture: The Roles of Employer. Operations Manager and Safety Professional. Journal of Safety Research. 41. 423-431.

Yang, C. C., Wang, Y. S., Chang, S. T., Guo, S.E. ve Huang, M. F. (2010). A Study on the Leadership Behaviour. Safety Culture and Safety Performance of the Healthcare Industry. World Academy of Science. Engineering and Technology. 3. 959-966.

Zohar, D. (1980). Safety Climate in Industrial Organisations: Theoretical and Applied Implications. Journal of Applied Psychology. 65. 96-102. 